Angela Mazzeo

ESTUDO DAS ALTERAÇÕES MORFOLÓGICAS E ESTRUTURAIS RENAIS EM DIFERENTES TEMPOS DE ISQUEMIA E TIPOS DE CLAMPEAMENTO DO PEDÍCULO VASCULAR RENAL

\author{
Dissertação apresentada à Sociedade \\ Beneficente Israelita Brasileira Albert \\ Einstein para obtenção do Título de Mestre \\ em Ciências da Saúde.
}

São Paulo 
Angela Mazzeo

\title{
ESTUDO DAS ALTERAÇÕES MORFOLÓGICAS E ESTRUTURAIS RENAIS EM DIFERENTES TEMPOS DE ISQUEMIA E TIPOS DE CLAMPEAMENTO DO PEDÍCULO VASCULAR RENAL
}

\author{
Dissertação apresentada à Sociedade \\ Beneficente Israelita Brasileira Albert \\ Einstein para obtenção do Título de Mestre \\ em Ciências da Saúde. \\ Orientador: Prof. Dr. Oskar Grau Kaufmann \\ Coorientadores: Prof. Dr. Oscar Pavão dos \\ Santos e Prof. Dr. Miguel Angelo Goés \\ Júnior
}

São Paulo 
M477e

Mazzeo, Angela

Estudo das alterações morfológicas e estruturais renais em diferentes tempos de isquemia e tipos de clampeamento do pedículo vascular renal / Angela Mazzeo. -- São Paulo, 2017.

xii, $35 \mathrm{f.}$, il.

Dissertação (Mestrado) - Sociedade Beneficente Israelita Brasileira Albert Einstein. Instituto de Ensino e Pesquisa Albert Einstein. Programa de Pós-Graduação em Ciências da Saúde.

Título em ingles: Study of morphological and renal structural changes in relation to different ischemic times and types of renal vascular pedicle clamping.

1. Isquemia renal. 2. Lesão renal. 3. Tempo de isquemia. 4.clampeamento.

NLM - WJ 342

Elaborada pelo Sistema Einstein Integrado de Bibliotecas 
SOCIEDADE BENEFICENTE ISRAELITA BRASILEIRA ALBERT EINSTEIN

Coordenador do Curso de Pós-Graduação: Prof. Dr. Luiz Vicente Rizzo 
Angela Mazzeo

\section{ESTUDO DAS ALTERAÇÕES MORFOLÓGICAS E ESTRUTURAIS RENAIS EM DIFERENTES TEMPOS DE ISQUEMIA E TIPOS DE CLAMPEAMENTO DO PEDÍCULO VASCULAR RENAL}

Presidente da banca: Prof. Dr. Oskar Grau Kaufmann

BANCA EXAMINADORA

Membros titulares:

Prof. Dr. Wilson Aguiar

Prof. Dr. Gustavo Caserta Lemos

Prof. Dr. Archimedes Nardozza Júnior

Membros suplentes:

Prof. Dr. Antonio Otero Gil

Prof. Dr. Leonardo Oliveira Reis

Aprovada em: 04/09/2017. 


\section{Dedicatória}

Dedico 100\% desta dissertação ao Dr. Miguel Angelo Goés Júnior, que me ensinou a beleza da disciplina de Nefrologia e lapidou meus conhecimentos nestes dois anos com aulas, artigos, livros e muitas horas de conselho, estando sempre presente (perto ou longe). Obrigada pela amizade, pela força nos dias ruins, por acreditar no meu potencial e por nunca me deixar desistir. 


\section{Agradecimentos}

Agradeço primeiramente ao Dr. Oskar Grau Kaufmann pela orientação, pelos ensinamentos, por mostrar o quão encantadora e desafiadora é a cirurgia urológica, pela paciência nos momentos difíceis e por acreditar em meu potencial. Muito obrigada!

Agradeço ao Dr. Oscar Pavão dos Santos por ter aceitado a coorientação deste projeto, pela atenção a mim dedicada, pelas orientações, por ter disponibilizado recursos (financeiros e materiais) sem os quais seria impossível a conclusão deste projeto e principalmente, obrigada por ter disponibilizado o Dr. Miguel Angelo Goés para me orientar e lapidar tecnicamente.

Agradeço à minha colega de experimentos e doutoranda Dra. Anna Sincos pelos ensinamentos de técnica cirúrgica, pela amizade, pelo engajamento em todas as fases do projeto e por sempre me estimular a acreditar e lutar pelos meus sonhos.

Agradeço à patologista Dra. Kátia Ramos Moreira Leite (FMUSP) pelos ensinamentos, por ter disponibilizado as instalações de seu laboratório bem como sua equipe de técnicos.

Agradeço ao Dr. Luis Moura, patologista do Hospital do Rim e Hipertensão (HRIM), pela oportunidade de estagiar em seu laboratório e aos seus técnicos Eduardo e Wagner pela amizade e por toda atenção e ensinamentos a mim ministrados.

Agradeço a todos os funcionários da Disciplina de Nefrologia da Escola Paulista de Medicina (UNIFESP) pelo apoio, ajuda e críticas construtivas, em especial à Dra. Marrie, Dr. Edgar, Pablo e Clara.

Agradeço a todos os funcionários do Centro de Experimentação e Treinamento em Cirurgia (CETEC) do Hospital Israelita Albert Einstein por todo o suporte e ajuda nas cirurgias, em especial à Dra. Valéria e a Dra. Lucina pela paciência e atenção dedicada.

Agradeço aos meus colegas pós-graduandos: Josi, Janaína e Danilo e Jander pela amizade, em especial a Andressa Saad pela parceria e pelos incontáveis cafés e Katherine Nates por toda ajuda e apoio nestes 2 anos de mestrado. 
Agradeço a todos os colaboradores da biblioteca do Hospital Israelita Albert Einstein (Edna e equipe) por toda ajuda e serviços prestados.

Agradeço ao Dr. Daniel Marchiori Remorini pelo apoio, pela paciência e pela compreensão neste último ano nos momentos de ausência.

Agradeço aos meus pais por sempre acreditarem e estimularem meus projetos.

Um agradecimento especial a Laudiceia Almeida, Coordenadora da Pós-Graduação do Instituto Israelita de Ensino e Pesquisa Albert Einstein, cujo apoio, paciência, conselhos e direcionamentos foram fundamentais para conclusão deste trabalho. 


\section{Sumário}

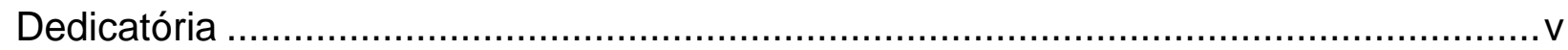

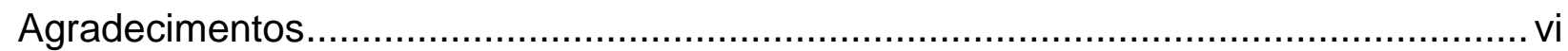

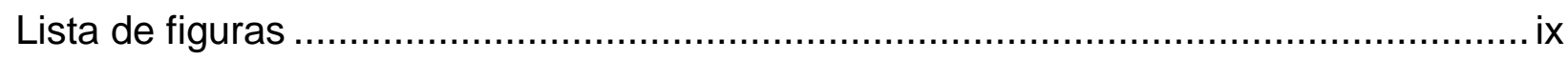

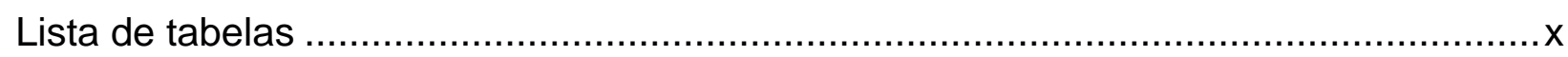

Lista de abreviaturas e símbolos .........................................................................

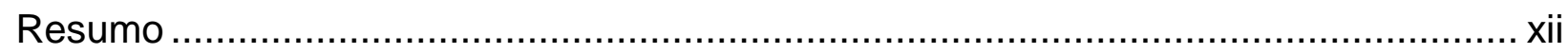

1 INTRODUÇÃO

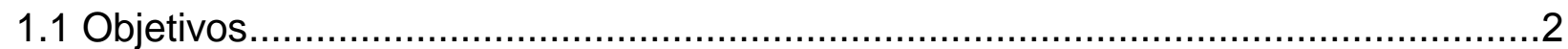

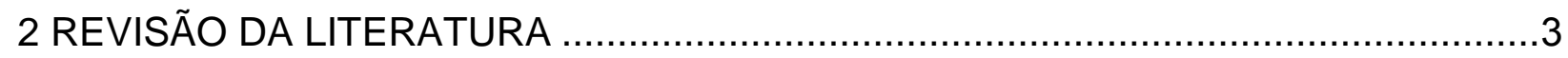

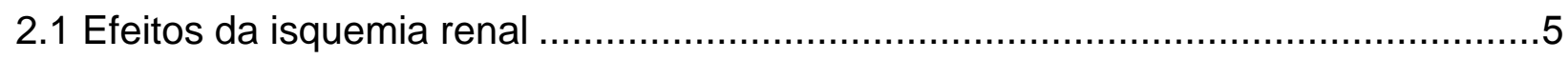

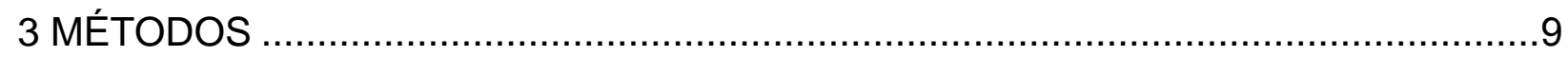

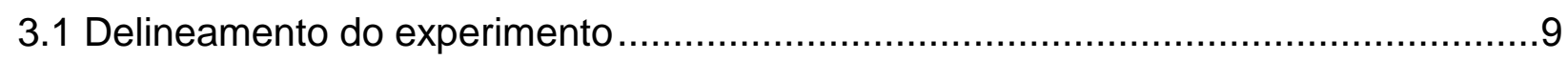

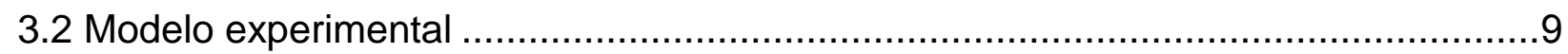

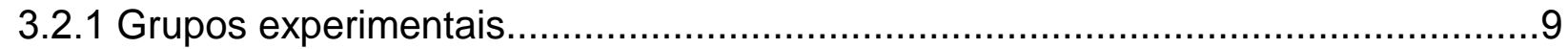

3.2.2 Procedimentos anestésicos e perioperatórios .................................................

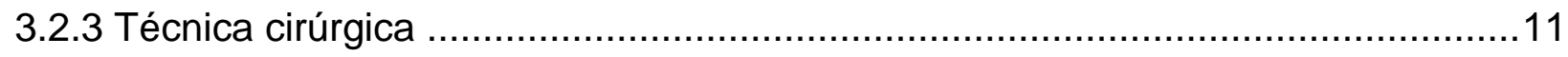

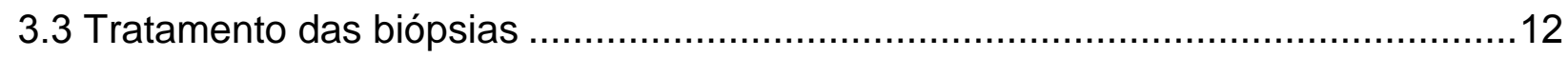

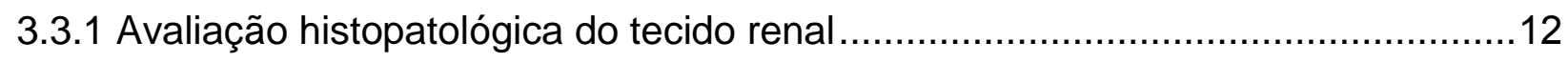

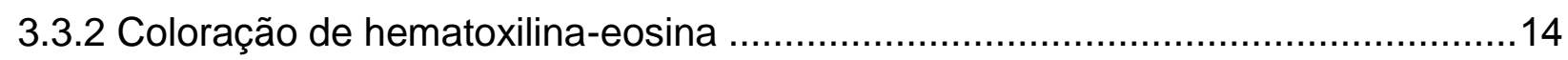

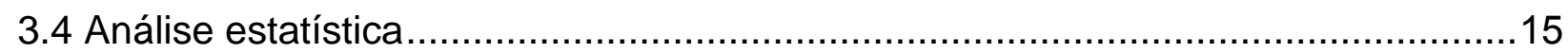

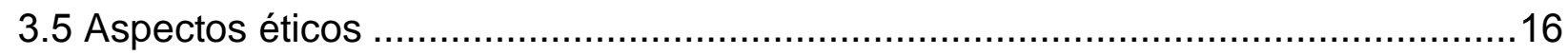

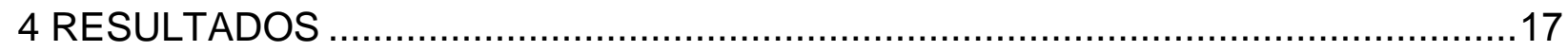

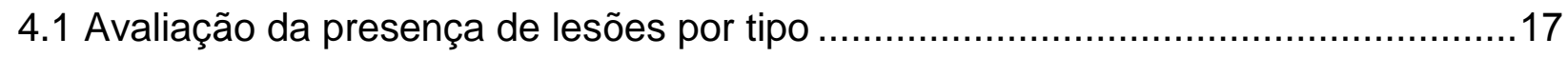

4.2 Avaliação da presença de lesões nas biópsias ..................................................23

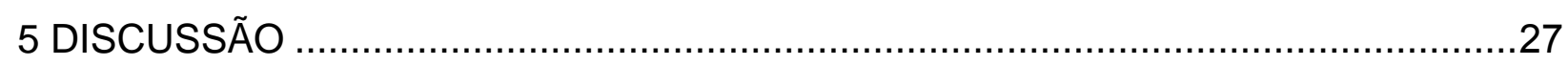

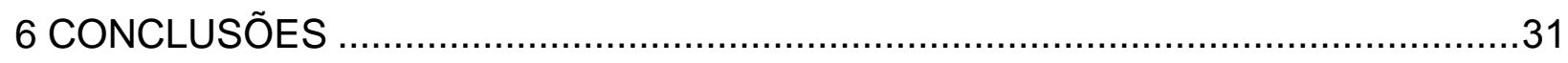

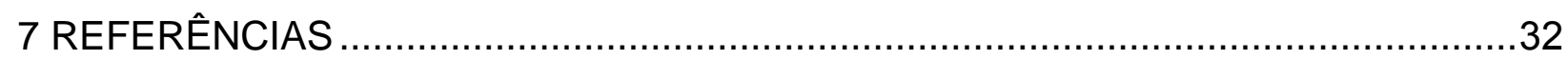

Abstract

Bibliografia consultada 


\section{Lista de figuras}

Figura 1. Animal anestesiado sob ventilação assistida no Centro de Experimentação e Treinamento em Cirurgia do Hospital Israelita Albert Einstein. 10

Figura 2. Punção de artéria femoral direita para monitorização de pressão arterial invasiva. 11

Figura 3. Dissecção do hilo renal e reparo das estruturas. 12

Figura 4. Coleta de biópsia renal com lâmina de bisturi frio .13

Figura 5. (A) Alterações degenerativas tubulares; (B) cilindros pigmentados; (C) congestão vascular e edema; (D) infiltrado neutrofílico intersticial; $(E)$ hemorragia intersticial..

Figura 6. Distribuição do número de biópsias com presença de congestão vascular e edema .18

Figura 7. Distribuição do número de biópsias com presença de infiltrado inflamatório intersticial.

Figura 8. Distribuição do número de biópsias com presença de alterações degenerativas de células tubulares

Figura 9. Distribuição do número de biópsias com presença de cilindros pigmentados

Figura 10. Distribuição do número de biópsias com hemorragia intersticial .22

Figura 11. Distribuição da proporção de biópsias com presença de lesão .23

Figura 12. Proporções estimadas de lesão e intervalos de confiança de $95 \%$ .25 


\section{Lista de tabelas}

Tabela 1. Distribuição da presença de congestão vascular e edema nas biópsias realizadas

Tabela 2. Distribuição da presença de infiltrado inflamatório intersticial nas biópsias realizadas 19

Tabela 3. Distribuição da presença de alterações degenerativas de células tubulares nas biópsias realizadas 20

Tabela 4. Distribuição da presença de cilindros pigmentados nas biópsias realizadas 21

Tabela 5. Distribuição do número de biópsias com hemorragia intersticial. .22

Tabela 6. Proporções estimadas para a presença de lesão nas biópsias realizadas ...24 Tabela 7. Resultados das comparações múltiplas entre momentos quanto à presença de lesões .26 


\section{Lista de abreviaturas e símbolos}

$\begin{array}{ll}\text { oC } & \text { Graus Celsius } \\ \mu \mathrm{g} & \text { Microgramas } \\ \mu \mathrm{m} & \text { Micrômetro } \\ \text { AAALAC } & \text { Association for Assessment and Accreditation of Laboratory Animal Care } \\ & \text { International } \\ \text { ATP } & \text { Adenosina-trifosfato } \\ \text { cm }^{3} & \text { Centímetros cúbicos } \\ \text { CETEC } & \text { Centro de Experimentação e Treinamento em Cirurgia } \\ \text { CEUA } & \text { Comissão de Ética para Uso de Animais } \\ \text { EEG } & \text { Equação de Estimação Generalizada } \\ \text { EROS } & \text { Espécies reativas de oxigênio } \\ \text { FMUSP } & \text { Faculdade de Medicina da Universidade São Paulo } \\ \text { Grupo A } & \text { Grupo artéria } \\ \text { Grupo AV } & \text { Grupo artéria e veia } \\ \text { HE } & \text { Hematoxilina-eosina } \\ \text { ICAM-1 } & \text { Molécula de adesão intercelular-1 } \\ \text { IR } & \text { Isquemia renal } \\ \text { IRA } & \text { Insuficiência renal aguda } \\ \text { Kg } & \text { Quilogramas } \\ \text { LIM55 } & \text { Laboratório de Investigação Médica número 55 (Urologia) } \\ \text { LRA } & \text { Lesão renal aguda } \\ \text { Mg } & \text { Miligramas } \\ \text { Min } & \text { Minutos } \\ \text { NTA } & \text { Necrose tubular aguda } \\ \text { Off-C } & \text { Ausência de clampeamento (off-clamp) } \\ \text { TCP } & \text { Túbulo contorcido proximal } \\ \text { TFG } & \text { Taxa de filtração glomerular } \\ \text { TNF } & \text { Fator de necrose tumoral } \\ \text { UI } & \text { Unidades internacionais } \\ \text { VCAM } & \text { Molécula de adesão vascular } \\ & \\ & \end{array}$




\section{Resumo}

Objetivo: Estudar as alterações morfológicas e estruturais renais em relação a diferentes tempos de isquemia e tipos de clampeamento do pedículo vascular renal. Métodos: Foram realizados experimentos simulando este procedimento nos quais foram utilizados 12 suínos que foram divididos em grupos contendo 6 animais cada: Grupo AV; realizado clampeamento unilateral de artéria e veia renal com rim contralateral usado como controle e Grupo A - clampeamento unilateral somente da artéria renal, com o rim contralateral também utilizado como controle. Após o clampeamento dos vasos foram realizadas biópsias seriadas do parênquima renal nos tempos $0,10,20,30,40,50,60,70,80$, e 90 minutos. Os tecidos foram submetidos à análise histopatológica a fim de identificar alterações estruturais e morfológicas. Resultados: Em ambos os grupos há correlação entre a ocorrência de lesões renais em função do tempo $(p<0,001)$, principalmente após 20 minutos de isquemia; verificouse maior frequência de lesões no Grupo A para todas as alterações celulares encontradas (congestão vascular e edema, infiltrado inflamatório intersticial, hemorragia intersticial e degeneração celular) com exceção na formação de cilindros pigmentados que foram evidenciados somente no Grupo AV. Conclusão: Como resultado deste estudo pudemos observar que o número de lesões derivadas da isquemia tem associação com o tempo de duração do insulto. Além disso, verificou-se que há diferença significativa entre os tipos de clampeamento, sendo que o Grupo AV apresentou menor frequência de lesões do que o Grupo A (apresentou maior número de lesões em menor intervalo de tempo de isquemia). Com relação ao tempo de segurança encontrado para Grupo A foi de 10 minutos e para o Grupo AV de 20 minutos. A frequência de alterações morfológicas e estruturais renais apresentou relação com o tipo de clampeamento e duração do mesmo. 


\section{INTRODUÇÃO}

A insuficiência renal aguda (IRA) é determinada pela rápida redução na taxa de filtração glomerular (TFG) que pode acontecer em um período de minutos a dias. As causas desta podem ser classificadas em 3 categorias: pré-renal, pós-renal (ou obstrutiva) e intrínseca (renal). ${ }^{(1)}$

Os rins possuem seu aporte de fluxo sanguíneo oriundo de $25 \%$ do débito cardíaco e, diferentemente de outros órgãos, são capazes de suportar uma redução aguda no seu aporte de fluxo sanguíneo em até $20 \%$ do habitual. No entanto devido à sua grande atividade metabólica (atividades de biotransformação, transporte endotelial, múltiplas vias enzimáticas, elevada taxa de consumo de oxigênio, reabsorção endotelial e transporte endotelial) tornam-se suscetíveis em condições isquêmicas. ${ }^{(2)}$

A lesão pré-renal é um tipo de resposta funcional à situação de hipoperfusão, na qual a estrutura do rim é preservada. Ocorre a hipoperfusão quando a pressão de perfusão é reduzida a um nível inferior à capacidade auto-regulatória do rim, fazendo com que vasoconstritores endógenos elevem a resistência arteriolar local, promovendo uma diminuição na TFG, o que resulta na insuficiência renal pré-renal. ${ }^{(3,4)}$

Na prática clínica e cirúrgica, a lesão pré-renal tem seus efeitos negativos potencializados em virtude da reperfusão renal que ocorre posteriormente a procedimentos cirúrgicos, tais como: nefrectomia parcial, transplantes renais, cirurgias de revascularização do miocárdio e cirurgias vasculares, assim como quadros clínicos de hipotensão e sepse. ${ }^{(5)}$

Em algumas cirurgias como a nefrectomia parcial, a interrupção do fluxo sanguíneo renal é um procedimento adotado rotineiramente. Nelas, o tempo de clampeamento pode levar a lesões isquêmicas irreversíveis do parênquima renal. ${ }^{(6,7)}$

A lesão isquêmica no rim geralmente resulta em dano às células do néfron e das células da vascularização renal, levando à IRA que só é diagnosticada quando essas perturbações fisiopatológicas atingem um grau suficiente para manifestar anormalidades bioquímicas na circulação (elevação de uréia e creatinina). Após a finalização da manobra cirúrgica, o fluxo sanguíneo é restabelecido e há reperfusão renal, a qual intensifica as lesões causadas pela isquemia por meio de 
produção de espécies reativas de oxigênio (EROS), ocorrência de desarranjo celular, hipercoagulabilidade e congestão da microcirculação. ${ }^{(8-12)}$

Em geral, a IRA derivada de procedimentos cirúrgicos apresenta caráter transitório, mas pode evoluir para doença renal crônica de acordo com a gravidade e a duração da lesão que está diretamente relacionada com o tempo de isquemia. O tempo de clampeamento renal seguro ainda é controverso e não há dados suficientes na literatura. ${ }^{(13,14)}$ Baseado neste cenário verifica-se que o grau da lesão renal pós-operatória é dependente do tempo de isquemia (minutos), sendo diretamente proporcional ao mesmo, ou seja, quanto menor for este tempo, menor será o dano isquêmico e sua repercussão clínica. ${ }^{(15,16)} \mathrm{O}$ tempo de segurança para realização destes procedimentos é vastamente discutido na literatura, variando entre 30-60 minutos. ${ }^{(17)}$

Outro tema controverso na literatura é a relação entre o risco de lesão renal de acordo com o tipo de clampeamento (oclusão do fluxo sanguíneo) realizado: apenas interrupção do fluxo arterial versus clampeamento arterial e venoso no rim ipsilateral ao procedimento. ${ }^{(18)}$

Ao analisar os estudos experimentais que abordam indução da isquemia renal (IR) na literatura, identificamos que grande parte destes estudos avalia a função renal antes e depois do procedimento cirúrgico, por meio de indicadores bioquímicos (ureia e creatinina) e avaliação histopatológica (coleta de biópsias) de forma que este acompanhamento pós-cirúrgico pode perdurar horas ou dias.

Entretanto, não foi identificado nenhum estudo que monitorava a integridade renal em função do tempo de isquemia em procedimentos cirúrgicos com a finalidade de identificar o intervalo de tempo no qual surgem as primeiras lesões renais por meio da realização de biópsias seriadas em intervalos específicos.

\subsection{Objetivos}

1. Estudar as alterações morfológicas e estruturais renais em relação a diferentes tempos de isquemia.

2. Analisar se há diferenças entre os diferentes tipos de clampeamento. 


\section{REVISÃO DA LITERATURA}

A indução da isquemia em cirurgias renais vem sendo foco de pesquisas científicas desde a década de 1970, utilizando modelos experimentais para elucidar métodos de preservação da função renal, de modo a reduzir os efeitos negativos do insulto isquêmico. ${ }^{(19,20)}$ Neste cenário várias abordagens são consideradas, tais como tipo de isquemia (fria ou quente), tipo de estudo (experimental ou clínico), tempo de isquemia, tipo de cirurgia, uso de artefatos farmacológicos e estratégias para interrupção do fluxo sanguíneo renal (tipos de clampeamento). ${ }^{(21)} \mathrm{A}$ presença de comorbidades tais como diabetes, hipertensão, tamanho e tipo do tumor a ser retirado, presença de rim solitário e alteração na TFG podem interferir no grau de lesão renal pós-operatória. ${ }^{(22)}$

O termo clampeamento é utilizado quando se promove a interrupção do fluxo sanguíneo renal utilizando um artefato do tipo grampo vascular (clamp). Esta manobra pode considerar o pinçamento da artéria renal isoladamente ou de todo hilo vascular (veia e artérias renais) sendo considerada uma técnica padrão ouro em cirurgias poupadoras de néfrons. Tal artifício permite a redução do fluxo sanguíneo no parênquima renal de modo a facilitar a ressecção bem como o fechamento do mesmo. ${ }^{(23)}$ As consequências da IR são potencializadas ao término do procedimento onde há reperfusão do fluxo sanguíneo provocando lesões vasculares e tubulares caracterizando assim a IRA. ${ }^{(24)}$

Até o presente momento não há consenso com relação ao tempo de duração do insulto isquêmico sem que haja qualquer tipo de alteração morfológica e estrutural das células renais (tempo de segurança). Há pesquisas que indicam uma relação direta entre tempo de isquemia e grau de alterações renais, entretanto estudos realizados por Klatte et al. indicam que não há relação entre estas variáveis, sendo o grau de integridade do parênquima renal responsável pelo nível de lesão. ${ }^{(25)}$

Um estudo vastamente comentado na literatura é realizado por Ward, ${ }^{(26)}$ o qual sugere que 30 minutos seria a faixa de tolerância para IR, porém o estudo possui limitações, não indicando por quanto tempo o rim suporta as alterações celulares do ponto de vista reversível. ${ }^{(27)}$ Além disto sugere que após este período seja iniciada a hipotermia renal (isquemia a frio) com temperatura abaixo de $15^{\circ} \mathrm{C}$. ${ }^{(26)}$ 
Modelos experimentais em suínos foram estudados por Parekh et al. que identificaram alteração na função renal após 72 horas do procedimento, estabelecendo 30 minutos como tempo de segurança verificando alteração na função renal após este tempo de corte. ${ }^{(28)}$ Neste mesmo tipo de modelo consideram a faixa de segurança entre 75 e 90 minutos em suínos quando o tipo de clampeamento envolver o pedículo vascular renal (artéria e veia). ${ }^{(29)}$

De acordo com o estudo realizado por Rocca utilizando rins humanos, observou-se que o tempo no qual as alterações tem início ocorre entre 20 a 30 minutos após início do insulto, provocando modificações celulares tais como alterações degenerativas, que são intensificadas após 60 minutos transcorridos, recomendando a adoção de 30 minutos como tempo de segurança. ${ }^{\left({ }^{30}\right)}$ A hipótese do tempo de segurança de 30 minutos também é sustentada por ensaios clínicos realizados por Simmons et al., considerando que o paciente em questão apresente uma função renal normal antes do procedimento cirúrgico, além de análises inferiores a 20 minutos que demonstram que não há alterações significativas na função renal. ${ }^{(3)}$ Choi et al. realizaram estudo com pacientes que realizaram nefrectomia parcial laparoscópica e robótica e verificou-se que a técnica cirúrgica exerce influência em termos de danos renais assim como o tempo de isquemia é o grande preditor das alterações renais. Neste estudo o tempo de corte identificado foi de 28 minutos, acima deste intervalo de tempo as alterações renais são observadas por até um ano após a execução do procedimento. ${ }^{(31)}$ Outro estudo, o qual avaliou 319 pacientes que realizaram nefrectomia parcial retirada vírgula por cirurgia aberta, identificou o tempo de corte de 25 minutos, cerca de 19\% desenvolveu IRA pós-operatório e 16\% apresentou redução da TFG. Aqueles pacientes que já possuíam alteração na TFG pré-operatória desenvolveram insuficiência renal crônica (razão de chances 1,05 para cada aumento de 1 minuto no tempo de duração de isquemia). ${ }^{(32)}$ É possível verificar que tanto para modelos humanos quanto animais, independentemente da técnica adotada o tempo de segurança relatado na maioria dos estudos foi de 30 minutos, no entanto ainda há controvérsias com relação à adoção deste valor de referência. Outro ponto importante a ser considerado é a reprodutibilidade dos modelos, pois conforme pesquisa realizada por Pahernik et al., as alterações renais são mais sutis em animais do que em humanos. Em razão disto defendo a hipótese de que o rim humano suportaria de 30 a 60 minutos de isquemia, apresentando apenas alterações sutis estruturais, sem que haja impacto na função renal. ${ }^{(33)}$ 
Com relação aos estudos acerca da interferência dos tipos de clampeamento na função renal, Thompson et al. fizeram um estudo retrospectivo em 362 pacientes, os quais foram submetidos a nefrectomias parciais que apresentaram maiores chances de desenvolver lesão renal aguda durante a fase pós-operatória quando a isquemia foi realizada por meio do clampeamento somente da artéria renal. ${ }^{(34)}$

Conforme estudo realizado por Doty et al. usando modelo suíno para comparar os dois tipos de clampeamento durante a indução da IRA somente artéria e artéria e veia, constatou-se que a manobra indutora quando realizada ocluindo somente artéria renal (procedimento realizado em cirurgia aberta) apresentou melhores resultados em relação ao outro tipo de oclusão, os resultados indicaram uma redução nas elevações dos níveis de creatinina sérica durante a fase pós-operatória (no qual há evento da reperfusão). Entretanto, tal informação ainda gera discussão quanto à sua reprodutibilidade clínica, haja vista que uma vez clampeada somente a artéria há riscos intrínsecos a este processo, tais como ocorrência de vasoespasmos, enquanto a interrupção do fluxo no conjunto artéria e veia reduzem a probabilidade de ocorrência de hemorragia venosa. Logo, ainda há controvérsias sobre qual é a melhor prática assim como o tempo de segurança a ser utilizado para este tipo de intervenção. ${ }^{(35)}$

Além dos métodos convencionais de clampeamento em decorrência dos efeitos prejudiciais da lesão isquêmica, conceitos como "aperto seletivo", ausência de clampeamento (Off-C) e isquemia zero foram introduzidos nos estudos com a finalidade de manter o máximo da integridade do parênquima renal. ${ }^{(36)}$

\subsection{Efeitos da isquemia renal}

A isquemia oriunda da hipoperfusão renal gera uma diminuição no aporte de oxigênio para as células renais, neste cenário as células tubulares consomem suas reservas de energia armazenadas na forma de adenosina-trifosfato (ATP), em decorrência do quadro de hipóxia instalado, e há liberação de agentes autoreguladores (óxido nítrico, prostaglandinas e vasodilatação mediada pelo sistema renina-angiotensina-aldosterona) com o objetivo de reduzir os efeitos da hipóxia celular e suas consequências (lesão celular). ${ }^{(37)}$ 
A isquemia derivada da alteração na hemodinâmica renal produz uma cascata de efeitos em nível celular (uma vez que todo estoque de ATP foi consumido, devido ao estado de anaerobiose) tal como alteração na atividade das bombas de sódio-potássio-ATPase e sódio-cálcio-ATPase, gerando uma descompensação do equilíbrio eletrolítico (aumento das concentrações de cálcio e sódio intracelular), de modo a promover aumento na pressão osmótica, reabsorção transepitelial de solutos, em especial o sódio, e causando um intumescimento celular que irá desencadear um edema agudo, além de perda da função mitocondrial e geração de EROS, caracterizando desta forma a lesão renal aguda (LRA) induzida por $\mathrm{IR}$. $^{(38)}$

Outras alterações morfológicas e estruturais são observadas durante a injúria renal, sendo estas: perda de estrutura da membrana plasmática e do citoesqueleto, desintegração da borda em escova das células epiteliais, reorganização das microvilosidades no citoplasma e da actina do domínio apical. Este rearranjo altera a resistência elétrica paracelular, afetando a aderência das células tubulares na membrana basale e causando mudança no arranjo tubular e seu deslocamento, gerando perda forças de Starling (associadas ao equilíbrio hídrico nestas regiões) e consequentemente obstrução do fluxo luminal. ${ }^{(39)}$

Com relação às alterações derivadas da perda de polaridade celular também há translocação para região apical da bomba de $\mathrm{Na}+/ K+-$ ATPase e das proteínas integrinas, afetando a excreção e reabsorção de sódio, fato que tem como consequências redução na taxa de reabsorção de íons no tubo contorcido proximal (TCP), sobrecarregando o túbulo contorcido distal e a mácula densa devido ao desequilíbrio do balanço eletroquímico dos demais íons. Baseado neste novo gradiente químico instalado ocorre a vasoconstrição das arteríolas aferentes, fato que promove a redução da TFG, causando elevação nos níveis de ureia e creatinina. ${ }^{(40)}$

Uma vez a lesão renal instalada há uma cascata de mediadores inflamatórios que são recrutados assim como espécies reativas de oxigênio, de forma a promover do dano tubular. ${ }^{(41)}$ Dentre estes mediadores citocinas, fator de necrose tumoral (TNF - tumor necrosis factor), moléculas de adesão epitelial, ocorrendo a translocação do epitélio por leucócitos com invasão do parênquima renal. ${ }^{(42)}$

De acordo com a literatura as células tubulares podem desenvolver três processos diferentes após a LRA derivada da isquemia: algumas não sofrem qualquer lesão, outras sofrem lesão e são "recuperadas" e outras morrem por necrose 
ou apoptose - sabe-se que ambas são desencadeadas por mecanismos distintos, sendo identificada a necrose por um processo inflamatório no qual a célula tem sua integridade da membrana perdida, ocorrência de edema citoplasmático e fragmentação celular; já na apoptose não ocorre processo inflamatório após a lise da célula, os corpos apoptóticos formados são prontamente fagocitados (caracterizada pela condensação citoplasmática e nuclear, fragmentação do DNA). No entanto estes dois tipos de processo de morte celular podem coexistir na mesma lesão e dependem da intensidade do insulto isquêmico, sendo que as áreas mais susceptíveis à necrose são: a alça ascendente espessa de Henle e o tubo contorcido proximal (alteração observada com maior frequência é a necrose tubular aguda - NTA), enquanto a apoptose ocorre com mais frequência no tubo contorcido distal, levando assim à disfunção renal. ${ }^{(43-45)}$

As alterações nas células endoteliais implicam na alteração da permeabilidade capilar devido à mudança no tônus vascular, levando a uma elevação na expressão de moléculas de adesão, entre elas: E-selectina, molécula de adesão intercelular-1 (ICAM-1), P-selectina e molécula de adesão vascular (VCAM). Por modularem a ligação dos leucócitos ao endotélio vascular, ocorre o extravasamento deles para o tecido renal durante a reperfusão renal (pós-isquêmica). Outros fatores de transcrição podem ser ativados como o fator $\mathrm{n}$, intensificando o processo inflamatório por mediarem citocinas, são ativados e induzem transcrição de citocinas e quimiocinas inflamatórias, sendo estes o fator nuclear Kappa B (NF-kB). ${ }^{(46)}$

As células endoteliais desenvolvem propriedade trombogênica devido à perda de sua propriedade antiaderente durante o quadro isquêmico, favorecendo a adesão leucocitária e posteriormente plaquetária no advento da reperfusão. ${ }^{(47)}$

$\mathrm{Na}$ literatura identificamos diferentes métodos para identificação das alterações celulares renais frente aos diferentes tempos de isquemia, uso de indicadores renais pré e pós-operatórios como ureia e creatinina sérica. ${ }^{(48)} \mathrm{A}$ creatinina sérica em especial é considerada técnica padrão ouro para diagnosticar alterações na função renal, no entanto ela possui limitações como marcador de LRA, sendo pouco sensível para detectar a fase precoce da doença, além de seus valores apresentarem alterações em situações tais como mudanças no metabolismo, sobrecarga de volume e depuração de drogas como cimetidina e moléculas orgânicas. ${ }^{(49)}$ Nos últimos anos grandes esforços têm sido empregados na pesquisa de novos biomarcadores como artifício para detecção precoce da IRA, todavia há uma série de variáveis inerentes ao 
processo que dificultam a validação de marcadores, tais como diferenças de gênero, idade, definição de valores de referência para diferentes patologias, requerendo maiores estudos para sua adoção. ${ }^{(49)}$ 
3 MÉTODOS

\subsection{Delineamento do experimento}

Foi realizado um estudo experimental controlado, no qual foram avaliadas as amostras de diferentes grupos de estudo em diferentes tempos de forma qualitativa.

\subsection{Modelo experimental}

O experimento foi realizado nas dependências do Centro de Experimentação e Treinamento em Cirurgia (CETEC) do Hospital Israelita Albert Einstein. Foi utilizado um quantitativo de 16 suínos fêmeas da raça Large-White com idade de aproximadamente 60 dias, pesando entre 25 a $30 \mathrm{~kg}$.

\subsubsection{Grupos experimentais}

A distribuição dos animais foi feita por grupos experimentais de acordo com a descrição abaixo:

- Grupo AV ( $n=8)$ : Os animais foram submetidos ao clampeamento unilateral (lado esquerdo) do pedículo vascular renal (artéria e veia renal) por 90 minutos e biópsias bilaterais seriadas do parênquima renal foram realizadas nos tempos $0,10,20,30,40$, $50,60,70,80$ e 90 minutos.

- Grupo A ( $n=8)$ : Os animais foram submetidos ao clampeamento unilateral (lado esquerdo) da artéria renal por 90 minutos e biópsias bilaterais seriadas do parênquima renal nos tempos $0,10,20,30,40,50,60,70,80$ e 90 minutos.

\subsubsection{Procedimentos anestésicos e perioperatórios}

O procedimento anestésico foi realizado sob supervisão de uma médica veterinária. Todos os animais foram pré-anestesiados com injeção intramuscular de Ketamina $(10,0 \mathrm{mg} / \mathrm{kg})$ e Midazolan $(0,25 \mathrm{mg} / \mathrm{kg})$, misturados na 
mesma seringa. Passados 15 minutos da injeção, a veia marginal da orelha foi cateterizada com cateter de calibre 20 ou 22 (BD Insystem, Becton Therapy Systems Inc., EUA), para servir de acesso venoso para a indução anestésica, que foi realizada com Tiopental $7 \mathrm{mg} / \mathrm{kg}$. A reposição hídrica de jejum foi calculada de acordo com o protocolo: dose inicial de $2 \mathrm{~mL} / \mathrm{Kg} / \mathrm{h}$ de cristalóide infusão rápida, com uma manutenção de $10 \mathrm{~mL} / \mathrm{kg} / \mathrm{h}$ de cristalóide durante a operação. Foram utilizados tubos endotraqueais tamanho 6,5 a 8,5 $\left(\right.$ Portex $^{\circledR}$ ) para a intubação dos animais (Figura 1). A anestesia foi mantida inalatória com Isoflurano de $2 \%$. Para ventilação, mantivemos um volume corrente é de $10 \mathrm{~mL} / \mathrm{kg}$, ajustado conforme parâmetros fisiológicos necessários. A analgesia foi mantida com fentanil, com dose inicial de $2,5 \mu \mathrm{g} / \mathrm{kg}$.

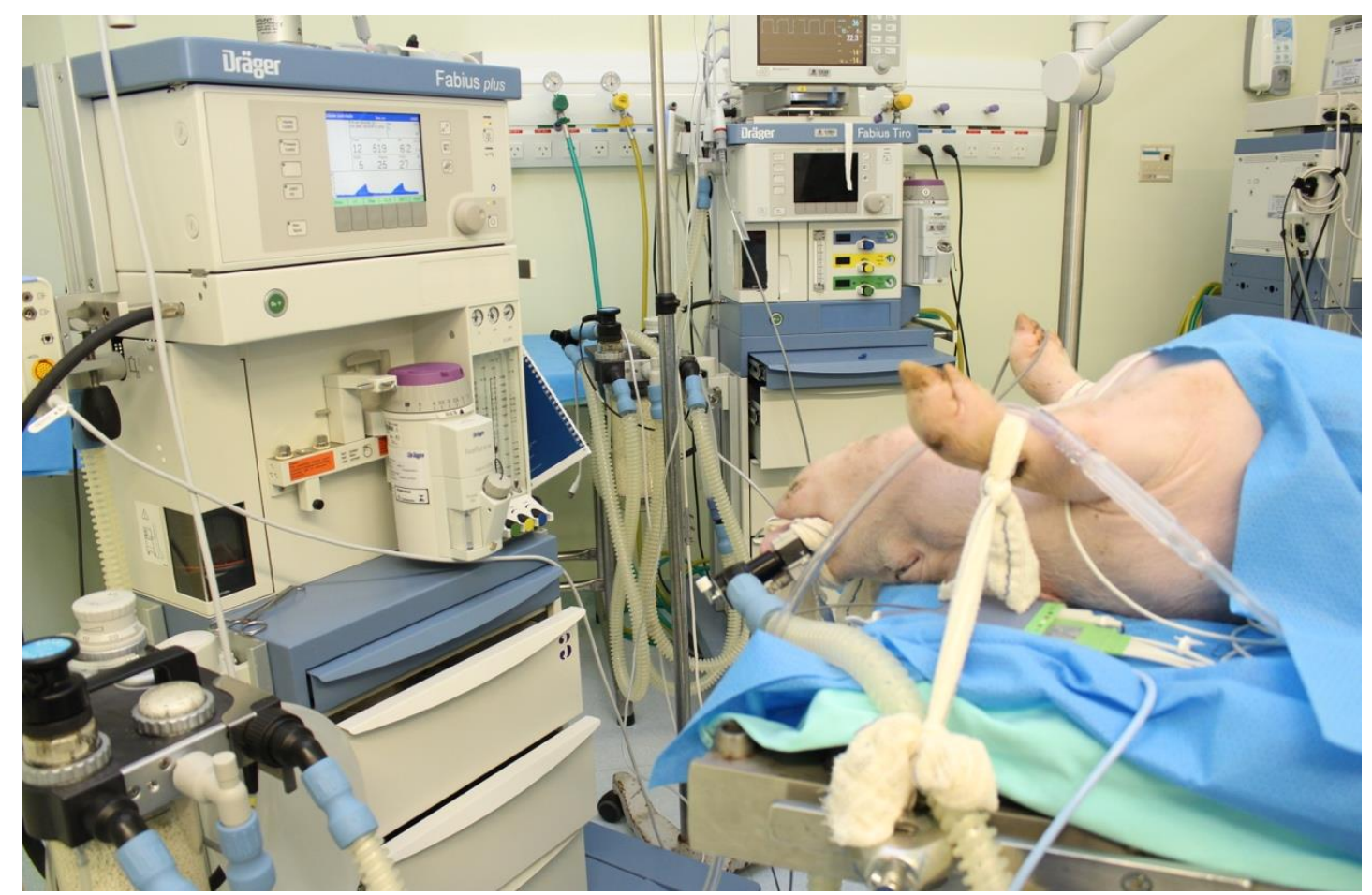

Figura 1. Animal anestesiado sob ventilação assistida no Centro de Experimentação e Treinamento em Cirurgia do Hospital Israelita Albert Einstein

As funções vitais e os parâmetros fisiológicos de respiração foram mantidos durante ventilação mecânica. A frequência cardíaca e pressão arterial invasiva foram avaliadas continuamente durante o procedimento, após acesso em artéria femoral comum direita guiada por ultrassonografia (Figura 2). Todos os animais receberam $150 \mathrm{Ul} / \mathrm{kg}$ de Heparina não fracionada sistêmica, antes do clampeamento do hilo renal. Apesar do uso de heparina em cirurgias urológicas ser controverso, nosso protocolo seguiu heparinização sistêmica devido ao potencial trombogênico desses 
animais, constatado em estudos experimentais prévios. ${ }^{(50,51)} \mathrm{O}$ uso de drogas vasoativas foi prescrito para evitar interferências no fluxo e na análise ecográfica. Hipotensão foi manejada apenas com reposição volêmica. Após o término da operação e coleta dos dados, ainda sob anestesia geral, os animais foram submetidos à eutanásia com overdose de Thiopental e Cloreto de Potássio 19,1\% endovenoso (dose de $15-30 \mathrm{mg} / \mathrm{kg}$ ).

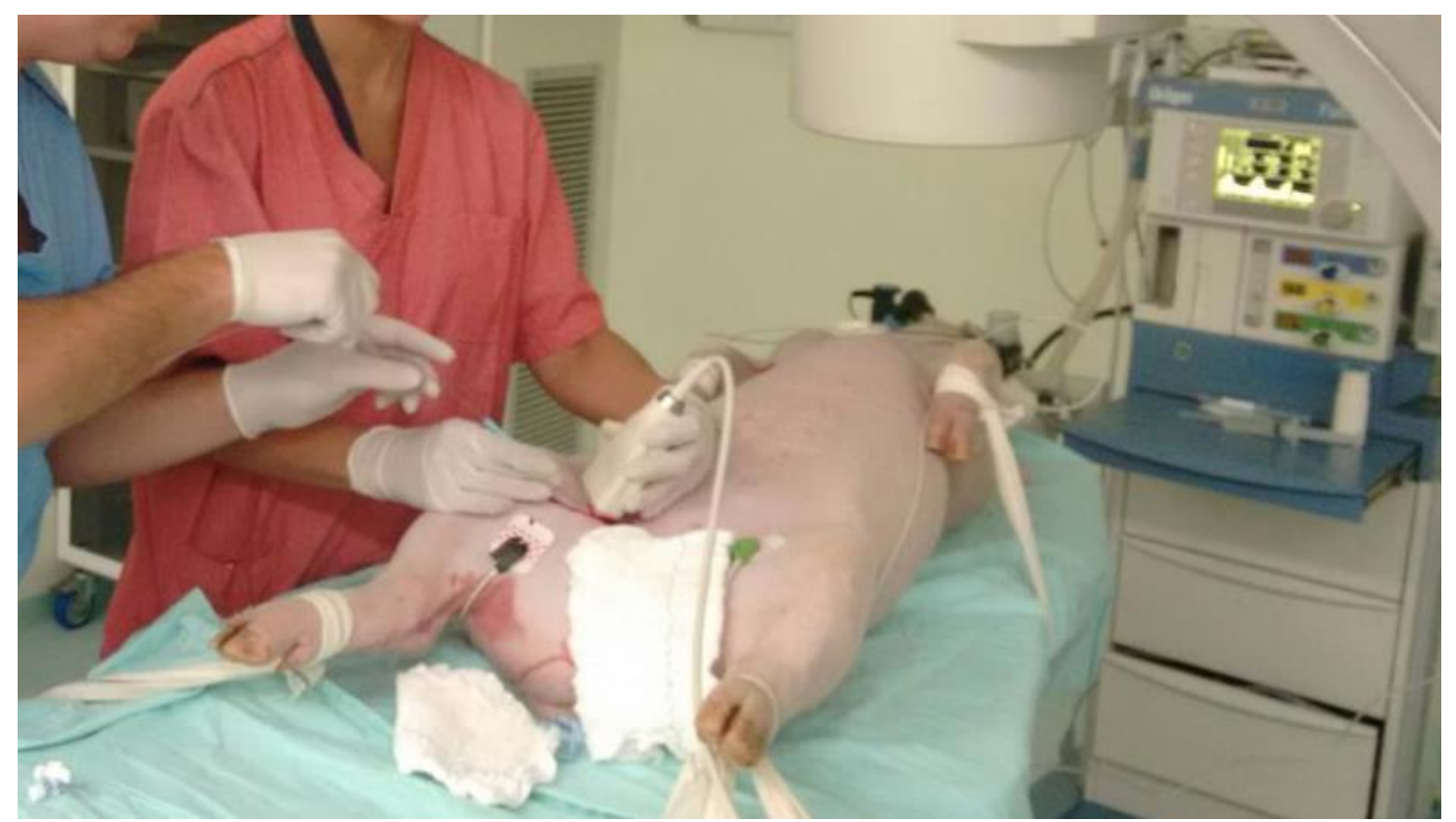

Figura 2. Punção de artéria femoral direita para monitorização de pressão arterial invasiva

\subsubsection{Técnica cirúrgica}

Com o animal anestesiado na posição de decúbito dorsal horizontal, realizou-se a higienização local e colocação dos campos cirúrgicos com técnica não estéril. Todos os animais foram submetidos à monitorização hemodinâmica com PA invasiva. Os animais foram divididos em dois grupos conforme citado previamente:

- Grupo AV - Total de 8 animais com clampeamento unilateral de artéria e veia renal. Rim contralateral foi usado como controle.

- Grupo A - Total de 8 animais com clampeamento unilateral da artéria renal. Rim contralateral foi usado como controle.

Efetuou-se laparotomia xifo-púbica mediana e acesso retroperitoneal com mobilização das alças após dissecção e reparo dos vasos renais (Figura 3). Após a certificação de que ambos os rins estavam adequados para análise, 
efetuou-se clampeamento do hilo renal esquerdo com clampe vascular tipo bulldog e o direito permaneceu como controle. A partir daí, foram realizadas biópsias seriadas do parênquima renal nos tempos $0,10,20,30,40,50,60,70,80$ e 90 minutos, em ambos os rins.

Todas as biópsias foram realizadas randomicamente com lâmina de bisturi número 11, com exérese de pequeno segmento do parênquima renal, medindo em torno de $1 \mathrm{~cm}^{3}$. Esse segmento biopsiado foi mantido em solução de formaldeído $10 \%$ para posterior confecção das lâminas e análise histológica.

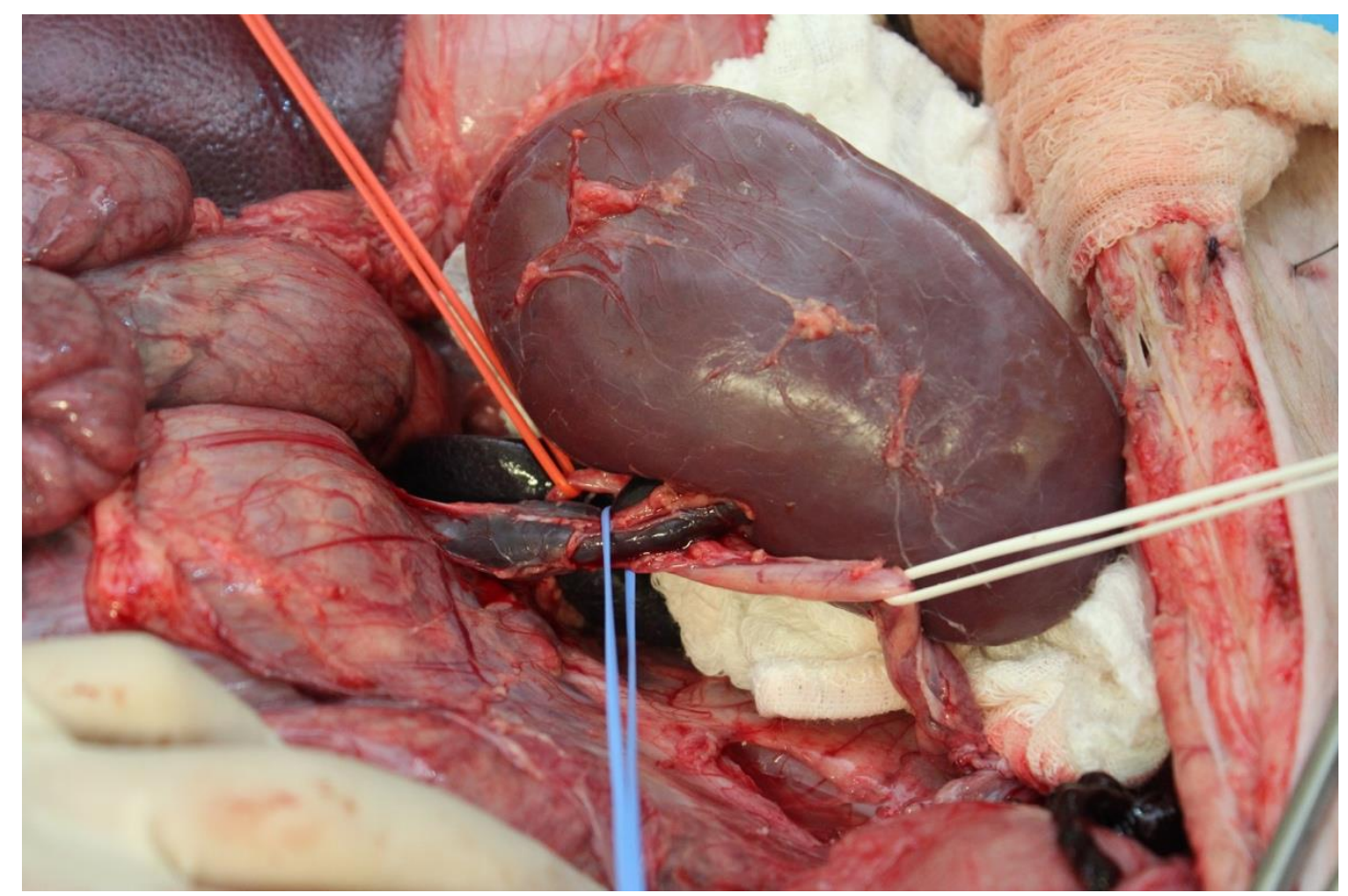

Fio em vermelho: artéria renal; em azul: veia renal; e em branco: pelve renal e ureter proximal.

Figura 3. Dissecção do hilo renal e reparo das estruturas

\subsection{Tratamento das biópsias}

Para verificar as alterações funcionais e estruturais foram selecionadas as seguintes técnicas histológicas para análise do material: coloração de hematoxilina-eosina (HE).

\subsubsection{Avaliação histopatológica do tecido renal}


As biópsias foram realizadas utilizando-se lâmina de bisturi frio para coleta de amostras em formato cuneiforme (Figura 4). O material foi armazenado individualmente em tubos do tipo Falcon contendo solução de formol 10\% e mantidos à temperatura ambiente até seu processamento no Laboratório de Investigação Médica da Disciplina de Urologia da Faculdade de Medicina da Universidade de São Paulo (LIM55 - FMUSP).

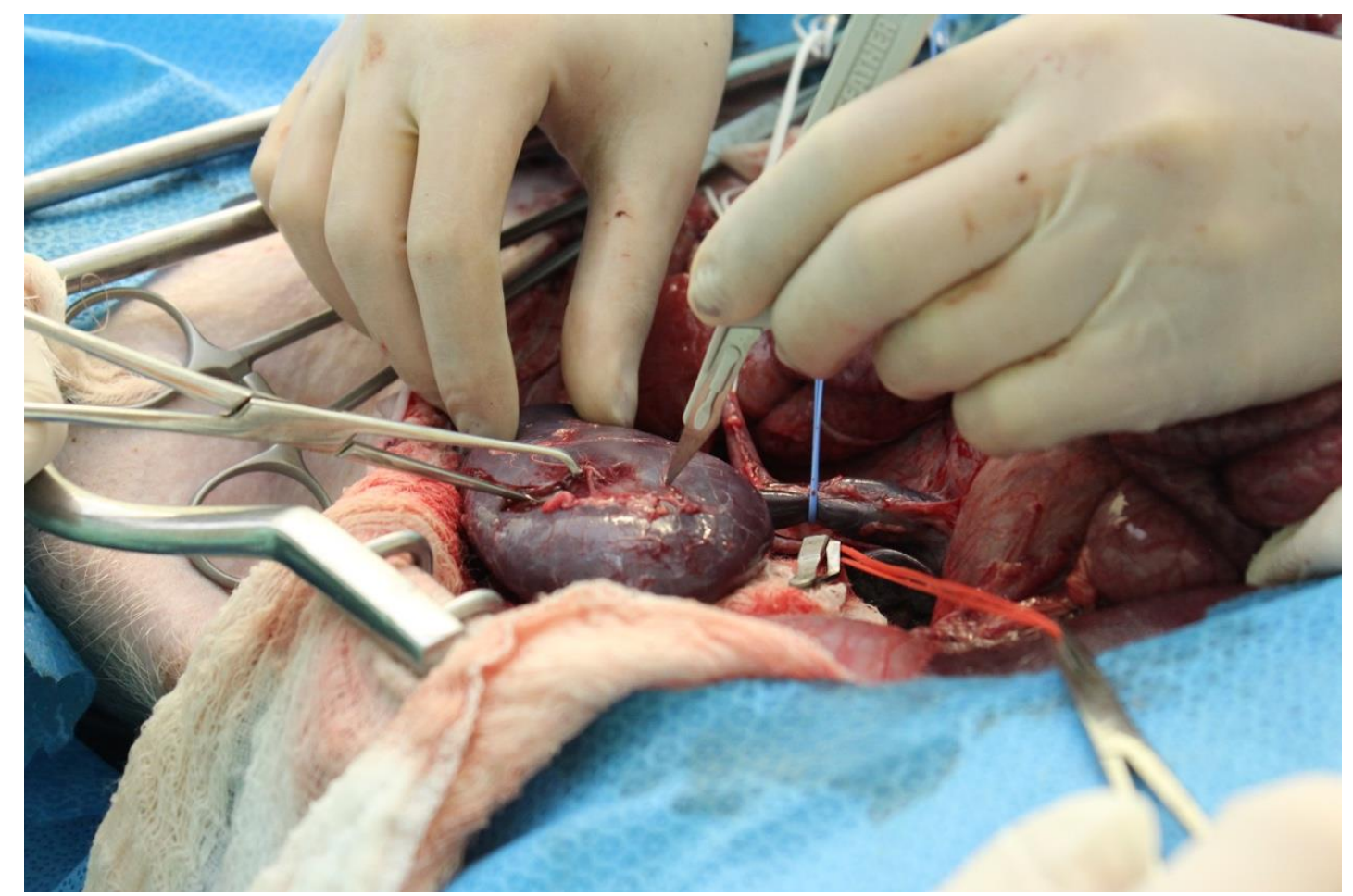

Figura 4. Coleta de biópsia renal com lâmina de bisturi frio

Conforme procedimento do laboratório o material foi processado conforme as etapas a seguir:

- Processamento automático dos tecidos: as biópsias foram identificadas e acondicionadas em cassetes do equipamento autotécnico denominado "Processador de Tecidos", neste ocorreu o processamento químico caracterizado banhos de diferentes agentes químicos por tempos determinados nos tecidos numa ordem sequencial, sendo esta: formol a 10\%, álcool absoluto, xilol e parafina da amostra a uma temperatura entre 60 e $80^{\circ} \mathrm{C}$.

- Inclusão na parafina: Após processamento químico os cassetes são retirados e colocados numa caneca elétrica que contêm parafina em seu interior, com a finalidade de preservar os tecidos até ter início o processo de inclusão. Os tecidos parafinados 
são retirados do cassete e emblocados (inseridos num bloco de metal juntamente com parafina líquida).

- Corte: Após resfriamento o bloco de parafina é retirado e os cortes histológicos foram realizados no equipamento micrótomo e fixados em lâminas. Posteriormente as lâminas foram armazenadas em berços e levadas para estufa a uma temperatura de 80 a $120^{\circ} \mathrm{C}$, por 15 minutos para desparafinização. Após transcorrer este intervalo de tempo as lâminas foram mergulhadas em xilol e álcool para retirar possíveis resíduos de parafina e seguir para coloração.

\subsubsection{Coloração de hematoxilina-eosina}

Foram enviados para histologia os fragmentos coletados aleatoriamente da região cortical do parênquima renal, durante a isquemia. As biópsias foram processadas de modo habitual e incluídas em parafina. Cortes de $3 \mu \mathrm{m}$ foram corados pela HE. Como as amostras foram coletadas em períodos muito próximos em relação ao tempo de isquemia, as anormalidades histológicas observadas foram muito discretas, necessitando de método mais objetivo para sua observação. Para isso as lâminas foram fotografadas em microscópio óptico $\left(\mathrm{NIKON}^{\circledR}\right)$ e as diferenças histológicas entre os grupos analisadas em sistema de imagem J-Image. Considerando que a NTA é a anormalidade mais frequentemente relacionada à isquemia, avaliamos: Os casos foram classificados qualitativamente de acordo com a presença da lesão em: Ausência de lesão: (0); Presença de lesão: (1), conforme figura 5.

1. Alterações degenerativas de células tubulares

2. Presença de cilindros pigmentados.

3. Congestão vascular e vacuolização de células tubulares (edema)

4. Infiltrado neutrofílico intersticial

5. Hemorragia intersticial 


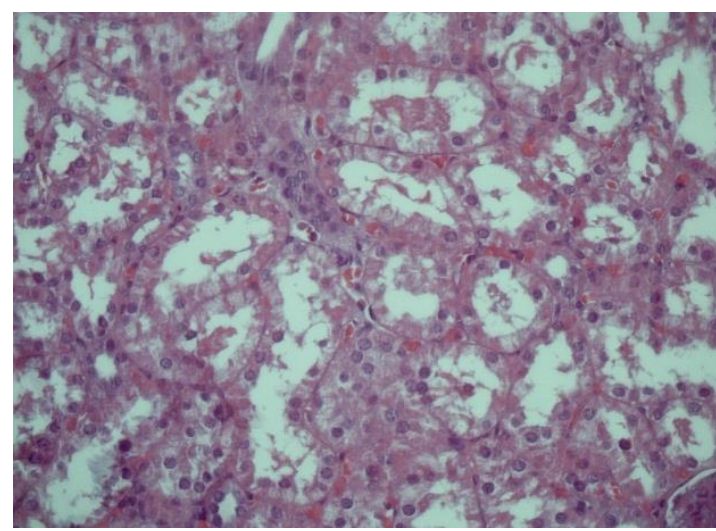

A

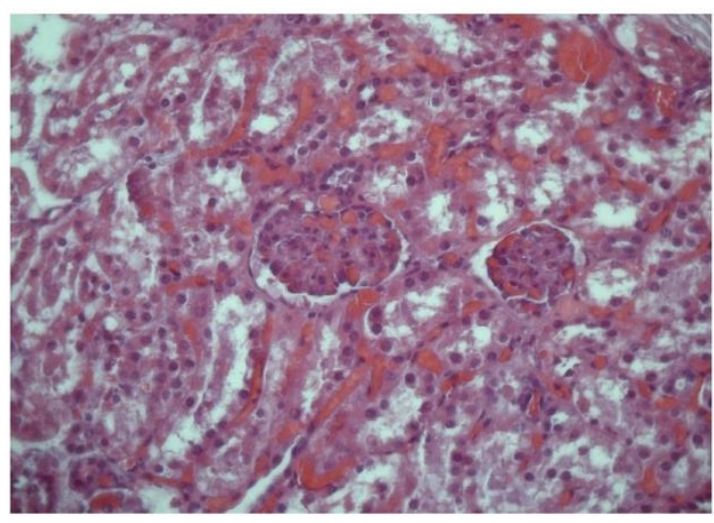

C

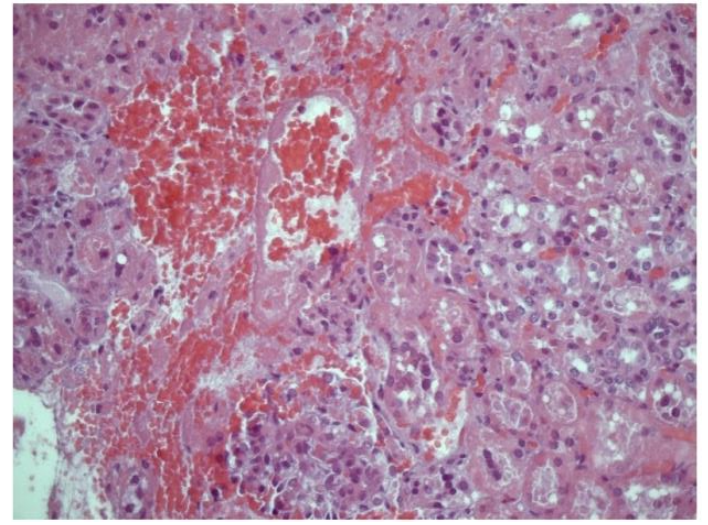

E

Figura 5. (A) Alterações degenerativas tubulares; (B) cilindros pigmentados; (C) congestão vascular e edema; (D) infiltrado neutrofílico intersticial; (E) hemorragia intersticial

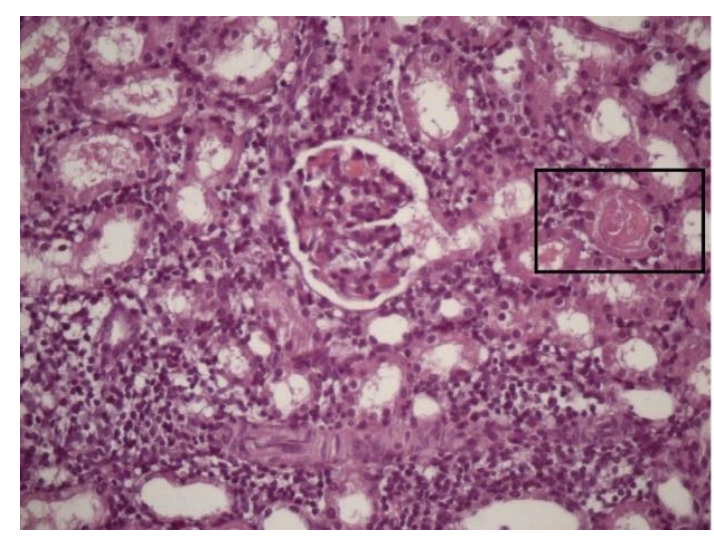

B

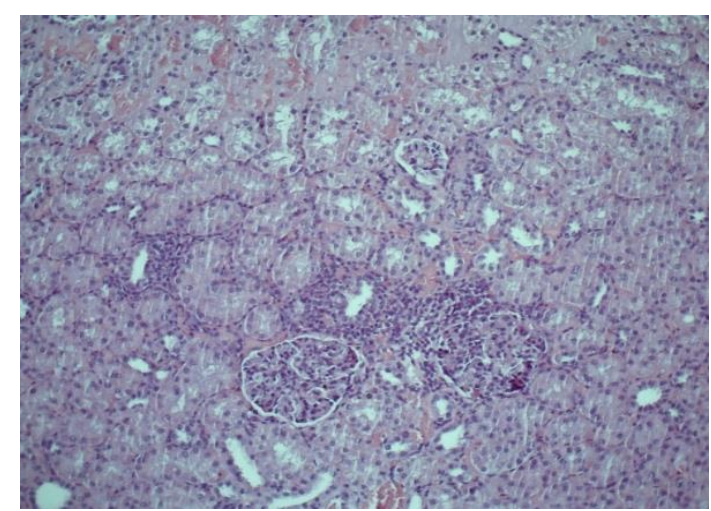

D

\subsection{Análise estatística}

A presença de lesões nas biópsias realizadas foi avaliada por um modelo de equações de estimação generalizadas (EEG) em todos os tempos de isquemia (basal e após o clampeamento), ${ }^{(52)}$ considerando a correlação entre as medidas em um mesmo animal em diferentes momentos de avaliação, entre os rins direito e esquerdo de um mesmo animal e entre as diferentes investigações de lesões. 
Este modelo considera a distribuição binomial, as variáveis explicativas foram o grupo de estudo, o momento de avaliação e o efeito de interação entre grupo e momento. ${ }^{(53,54)}$

Os resultados foram apresentados por proporções estimadas e erros padrão, além de intervalos de confiança de 95\%. Nos casos de comparações múltiplas os valores de $\mathrm{p}$ foram corrigidos pelo método de Bonferroni sequencial. As análises foram realizadas com o programa SPSS (IBM Corp, 2016) e considerando nível de significância $5 \%$. $^{(55,56)}$

\subsection{Aspectos éticos}

Este estudo foi realizado no CETEC, acreditado pela Association for Assessment and Accreditation of Laboratory Animal Care International (AAALAC), entre março de 2016 e dezembro de 2016. O estudo foi aprovado pelo comitê de ética e pesquisa do Hospital Israelita Albert Einstein e pela Comissão de Ética na Utilização Animal (CEUA) número 2617. Foram rigorosamente adotadas e seguidas as recomendações e normatizações prescritas pelo Decreto 6.899, datado de 15 de julho de 2009, para uso de animais em experimentos científicos e para proteção desses animais. 


\section{RESULTADOS}

\subsection{Avaliação da presença de lesões por tipo}

Ao realizar análise dos achados histológicos verificamos que ocorriam alterações celulares de formas distintas: ora eram encontradas em determinado grupo em diferentes momentos, ora não eram encontradas em nenhum dos grupos de estudo, em virtude deste perfil amostral não foi possível avaliar efeitos de grupo e momento por meio de métodos inferenciais separadamente por tipo de lesão.

Com base na análise descritiva identificamos uma prevalência de lesões no Grupo A em relação ao Grupo AV dos cinco tipos de lesões celulares encontradas nas biópsias renais (congestão vascular e edema, infiltrado inflamatório intersticial, alterações degenerativas, cilindros pigmentados e hemorragia intersticial) somente a formação de cilindros pigmentados foi observada no Grupo AV (tanto no rim isquêmico quanto no rim controle).

No Grupo A a presença de infiltrado inflamatório intersticial e de hemorragia intersticial ocorreu numa proporção de quatro em oito biópsias enquanto no Grupo AV observamos o máximo de duas entre oito biópsias. Já as alterações degenerativas foram mais frequentes após 20 minutos de isquemia também no Grupo A tanto no rim isquêmico como no controle.

A hemorragia intersticial aparenta ser mais frequente no Grupo A, tanto no rim isquêmico como no controle.

Nas tabelas de número 1 a 5 e figuras de número 6 a 10 foram apresentadas as distribuições da presença das lesões celulares encontradas em função do tempo para rins isquêmicos e controles e por tipo de clampeamento. 
Tabela 1. Distribuição da presença de congestão vascular e edema nas biópsias realizadas

\begin{tabular}{lcccc}
\hline & \multicolumn{4}{c}{ Grupo de estudo } \\
\cline { 2 - 5 } $\begin{array}{l}\text { Momento } \\
\text { (min) }\end{array}$ & \multicolumn{2}{c}{$\begin{array}{c}\text { Artéria } \\
(\mathbf{n = 8})\end{array}$} & $\begin{array}{c}\text { Artéria e Veia } \\
(\mathbf{n}=8)\end{array}$ \\
\cline { 2 - 5 } & $\begin{array}{c}\text { Rim esquerdo } \\
\text { (Isquêmico) } \\
\mathbf{n}(\%)\end{array}$ & $\begin{array}{c}\text { Rim direito } \\
\text { (Controle) } \\
\mathbf{n}(\%)\end{array}$ & $\begin{array}{c}\text { Rim esquerdo } \\
\text { (Isquêmico) } \\
\mathbf{n}(\%)\end{array}$ & $\begin{array}{c}\text { Rim direito } \\
\text { (Controle) } \\
\mathbf{n}(\%)\end{array}$ \\
\hline 0 & $5(62,5)$ & $2(25,0)$ & $2(25,0)$ & $2(25,0)$ \\
10 & $8(100,0)$ & $6(75,0)$ & $2(25,0)$ & $2(25,0)$ \\
20 & $8(100,0)$ & $7(87,5)$ & $4(50,0)$ & $5(62,5)$ \\
30 & $8(100,0)$ & $7(87,5)$ & $4(50,0)$ & $3(37,5)$ \\
40 & $8(100,0)$ & $8(100,0)$ & $5(62,5)$ & $3(37,5)$ \\
50 & $8(100,0)$ & $8(100,0)$ & $7(87,5)$ & $6(75,0)$ \\
60 & $8(100,0)$ & $8(100,0)$ & $6(75,0)$ & $5(62,5)$ \\
70 & $8(100,0)$ & $7(87,5)$ & $7(87,5)$ & $5(62,5)$ \\
80 & $8(100,0)$ & $8(100,0)$ & $7(87,5)$ & $6(75,0)$ \\
90 & $7(87,5)$ & $7(87,5)$ & $7(87,5)$ & $5(62,5)$ \\
\hline
\end{tabular}

Dados descritos por números de biópsias e porcentagem sobre o total de biópsias.

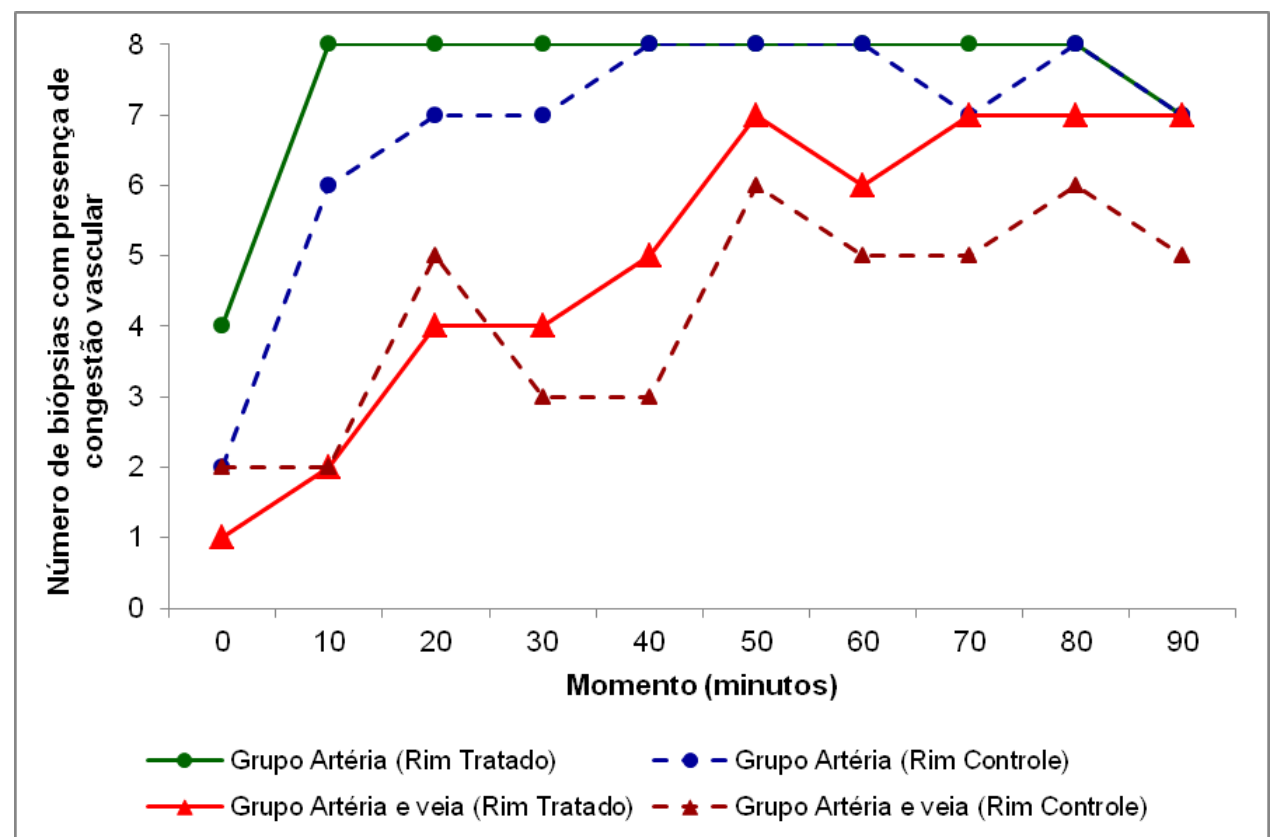

Figura 6. Distribuição do número de biópsias com presença de congestão vascular e edema 
Tabela 2. Distribuição da presença de infiltrado inflamatório intersticial nas biópsias realizadas

\begin{tabular}{lcccc}
\hline & \multicolumn{4}{c}{ Grupo de estudo } \\
\cline { 2 - 5 } $\begin{array}{l}\text { Momento } \\
\text { (min) }\end{array}$ & \multicolumn{2}{c}{$\begin{array}{c}\text { Artéria } \\
(\mathbf{n}=\mathbf{8})\end{array}$} & $\begin{array}{c}\text { Artéria e Veia } \\
(\mathbf{n = 8})\end{array}$ \\
\cline { 2 - 5 } & $\begin{array}{c}\text { Rim esquerdo } \\
\text { (Isquêmico) } \\
\mathbf{n}(\%)\end{array}$ & $\begin{array}{c}\text { Rim direito } \\
(\text { Controle) } \\
\mathbf{n}(\%)\end{array}$ & $\begin{array}{c}\text { Rim esquerdo } \\
\text { (Isquêmico) } \\
\mathbf{n}(\%)\end{array}$ & $\begin{array}{c}\text { Rim direito } \\
\text { (Controle) } \\
\mathbf{n}(\%)\end{array}$ \\
\hline 0 & $1(12,5)$ & $0(0,0)$ & $0(0,0)$ & $1(12,5)$ \\
10 & $0(0,0)$ & $0(0,0)$ & $0(0,0)$ & $0(0,0)$ \\
20 & $2(25,0)$ & $0(0,0)$ & $1(12,5)$ & $0(0,0)$ \\
30 & $2(25,0)$ & $4(50,0)$ & $2(25,0)$ & $1(12,5)$ \\
40 & $4(50,0)$ & $1(12,5)$ & $1(12,5)$ & $1(12,5)$ \\
50 & $4(50,0)$ & $2(25,0)$ & $1(12,5)$ & $0(0,0)$ \\
60 & $2(25,0)$ & $1(12,5)$ & $1(12,5)$ & $0(0,0)$ \\
70 & $2(25,0)$ & $2(25,0)$ & $2(25,0)$ & $0(0,0)$ \\
80 & $2(25,0)$ & $2(25,0)$ & $2(25,0)$ & $0(0,0)$ \\
90 & $1(12,5)$ & $1(12,5)$ & $2(25,0)$ & $1(12,5)$ \\
\hline
\end{tabular}

Dados descritos por números de biópsias e porcentagem sobre o total de biópsias.

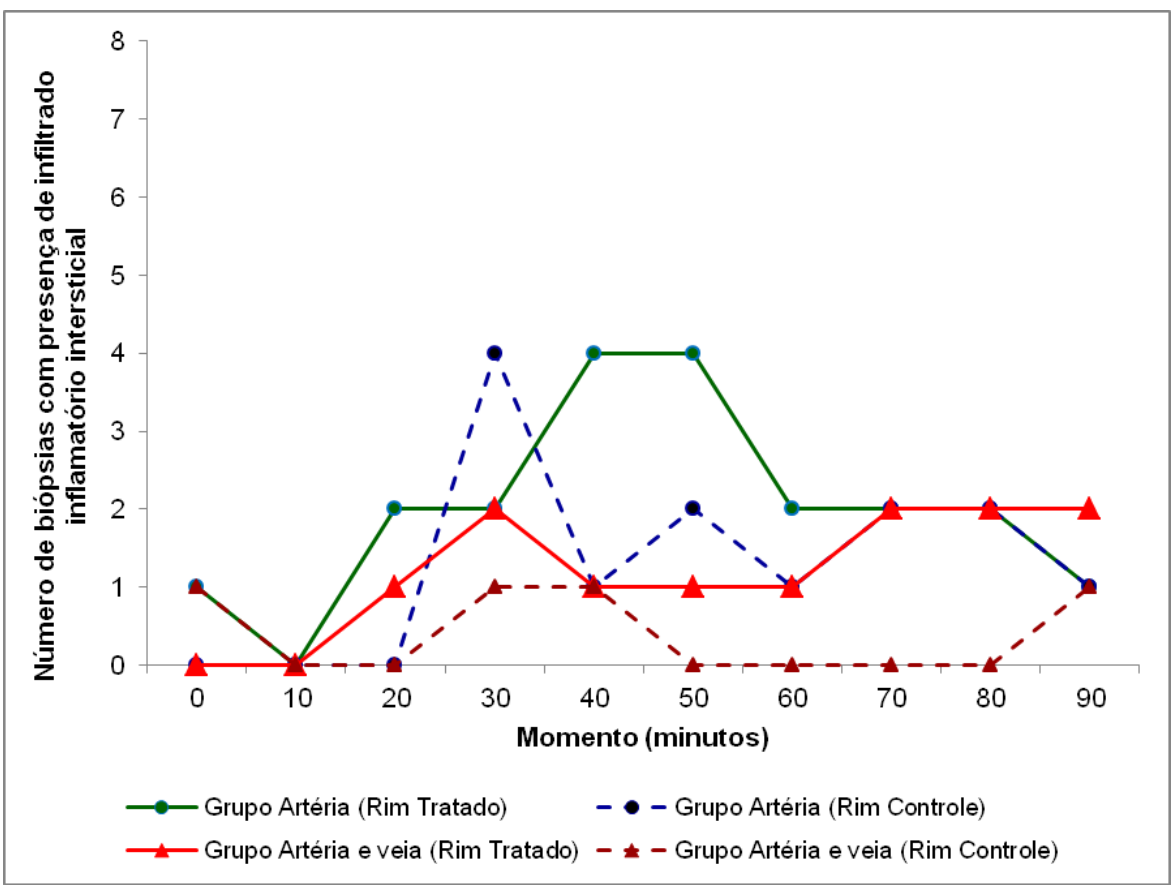

Figura 7. Distribuição do número de biópsias com presença de infiltrado inflamatório intersticial 
Tabela 3. Distribuição da presença de alterações degenerativas de células tubulares nas biópsias realizadas

\begin{tabular}{|c|c|c|c|c|}
\hline \multirow{3}{*}{$\begin{array}{l}\text { Momento } \\
\text { (min) }\end{array}$} & \multicolumn{4}{|c|}{ Grupo de estudo } \\
\hline & \multicolumn{2}{|c|}{$\begin{array}{c}\text { Artéria } \\
(\mathrm{n}=8)\end{array}$} & \multicolumn{2}{|c|}{$\begin{array}{c}\text { Artéria e Veia } \\
(n=8)\end{array}$} \\
\hline & $\begin{array}{c}\text { Rim esquerdo } \\
\text { (Isquêmico) } \\
\text { n(\%) }\end{array}$ & $\begin{array}{c}\text { Rim direito } \\
(\text { Controle) } \\
n(\%)\end{array}$ & $\begin{array}{c}\text { Rim esquerdo } \\
\text { (Isquêmico) } \\
\text { n(\%) }\end{array}$ & $\begin{array}{c}\text { Rim direito } \\
\text { (Controle) } \\
\mathrm{n}(\%)\end{array}$ \\
\hline 0 & $1(12,5)$ & $1(12,5)$ & $0(0,0)$ & $1(12,5)$ \\
\hline 10 & $2(25,0)$ & $2(25,0)$ & $2(25,0)$ & $0(0,0)$ \\
\hline 20 & $4(50,0)$ & $3(37,5)$ & $3(37,5)$ & $2(25,0)$ \\
\hline 30 & $5(62,5)$ & $5(62,5)$ & $5(62,5)$ & $4(50,0)$ \\
\hline 40 & $5(62,5)$ & $5(62,5)$ & $6(75,0)$ & $4(50,0)$ \\
\hline 50 & $8(100,0)$ & $5(62,5)$ & $5(62,5)$ & $4(50,0)$ \\
\hline 60 & $7(87,5)$ & $6(75,0)$ & $5(62,5)$ & $5(62,5)$ \\
\hline 70 & $7(87,5)$ & $7(87,5)$ & $6(75,0)$ & $5(62,5)$ \\
\hline 80 & $8(100,0)$ & $6(75,0)$ & $5(62,5)$ & $6(75,0)$ \\
\hline 90 & $7(87,5)$ & $6(75,0)$ & $5(62,5)$ & $4(50,0)$ \\
\hline
\end{tabular}

Dados descritos por números de biópsias e porcentagem sobre o total de biópsias.

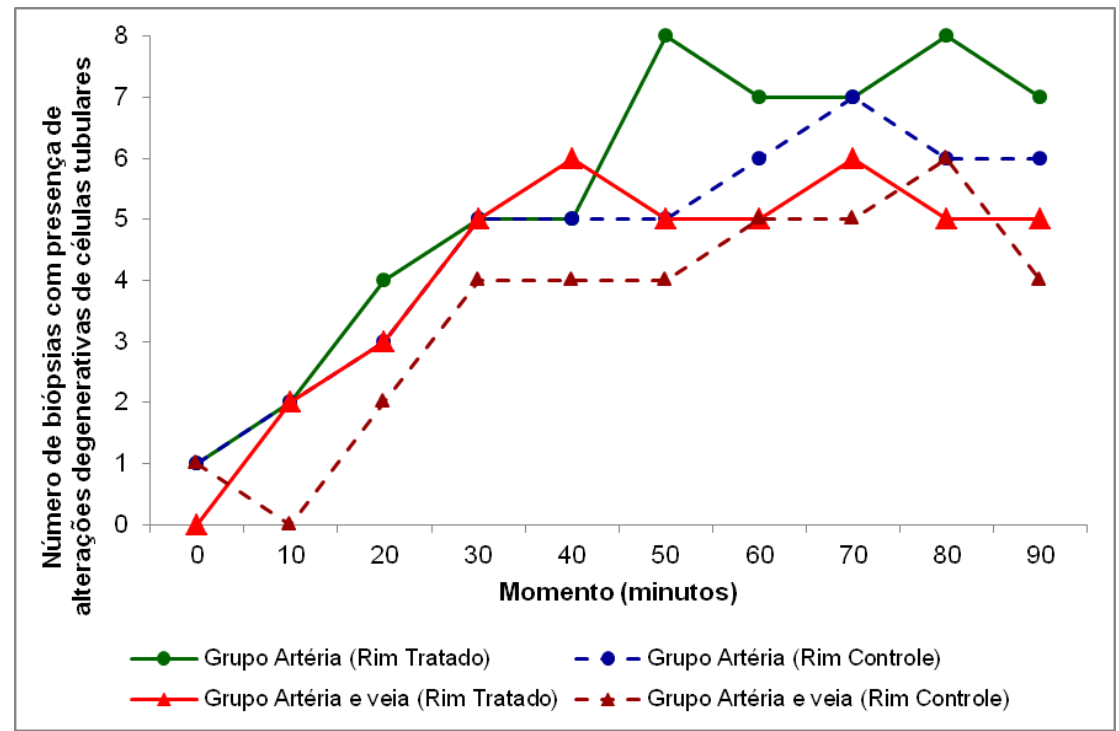

Figura 8. Distribuição do número de biópsias com presença de alterações degenerativas de células tubulares 
Tabela 4. Distribuição da presença de cilindros pigmentados nas biópsias realizadas

\begin{tabular}{lcccc}
\hline & \multicolumn{4}{c}{ Grupo de estudo } \\
\cline { 2 - 5 } $\begin{array}{l}\text { Momento } \\
\text { (min) }\end{array}$ & \multicolumn{2}{c}{$\begin{array}{c}\text { Artéria } \\
(\mathbf{n}=\mathbf{8})\end{array}$} & $\begin{array}{c}\text { Artéria e Veia } \\
(\mathbf{n}=\mathbf{8})\end{array}$ \\
\cline { 2 - 5 } & $\begin{array}{c}\text { Rim esquerdo } \\
\text { (Isquêmico) } \\
\mathbf{n}(\%)\end{array}$ & $\begin{array}{c}\text { Rim direito } \\
\text { (Controle) } \\
\mathbf{n}(\%)\end{array}$ & $\begin{array}{c}\text { Rim esquerdo } \\
\text { (Isquêmico) } \\
\mathbf{n}(\%)\end{array}$ & $\begin{array}{c}\text { Rim direito } \\
\text { (Controle) } \\
\mathbf{n}(\%)\end{array}$ \\
\hline 0 & $0(0,0)$ & $0(0,0)$ & $0(0,0)$ & $0(0,0)$ \\
10 & $0(0,0)$ & $0(0,0)$ & $1(12,5)$ & $1(12,5)$ \\
20 & $1(12,5)$ & $0(0,0)$ & $1(12,5)$ & $0(0,0)$ \\
30 & $1(12,5)$ & $0(0,0)$ & $2(25,0)$ & $3(37,5)$ \\
40 & $1(12,5)$ & $0(0,0)$ & $2(25,0)$ & $1(12,5)$ \\
50 & $1(12,5)$ & $0(0,0)$ & $1(12,5)$ & $1(12,5)$ \\
60 & $0(0,0)$ & $0(0,0)$ & $4(50,0)$ & $2(25,0)$ \\
70 & $0(0,0)$ & $0(0,0)$ & $4(50,0)$ & $2(25,0)$ \\
80 & $0(0,0)$ & $0(0,0)$ & $4(50,0)$ & $1(12,5)$ \\
90 & $1(12,5)$ & $0(0,0)$ & $5(62,5)$ & $1(12,5)$ \\
\hline 0
\end{tabular}

Dados descritos por números de biópsias e porcentagem sobre o total de biópsias.

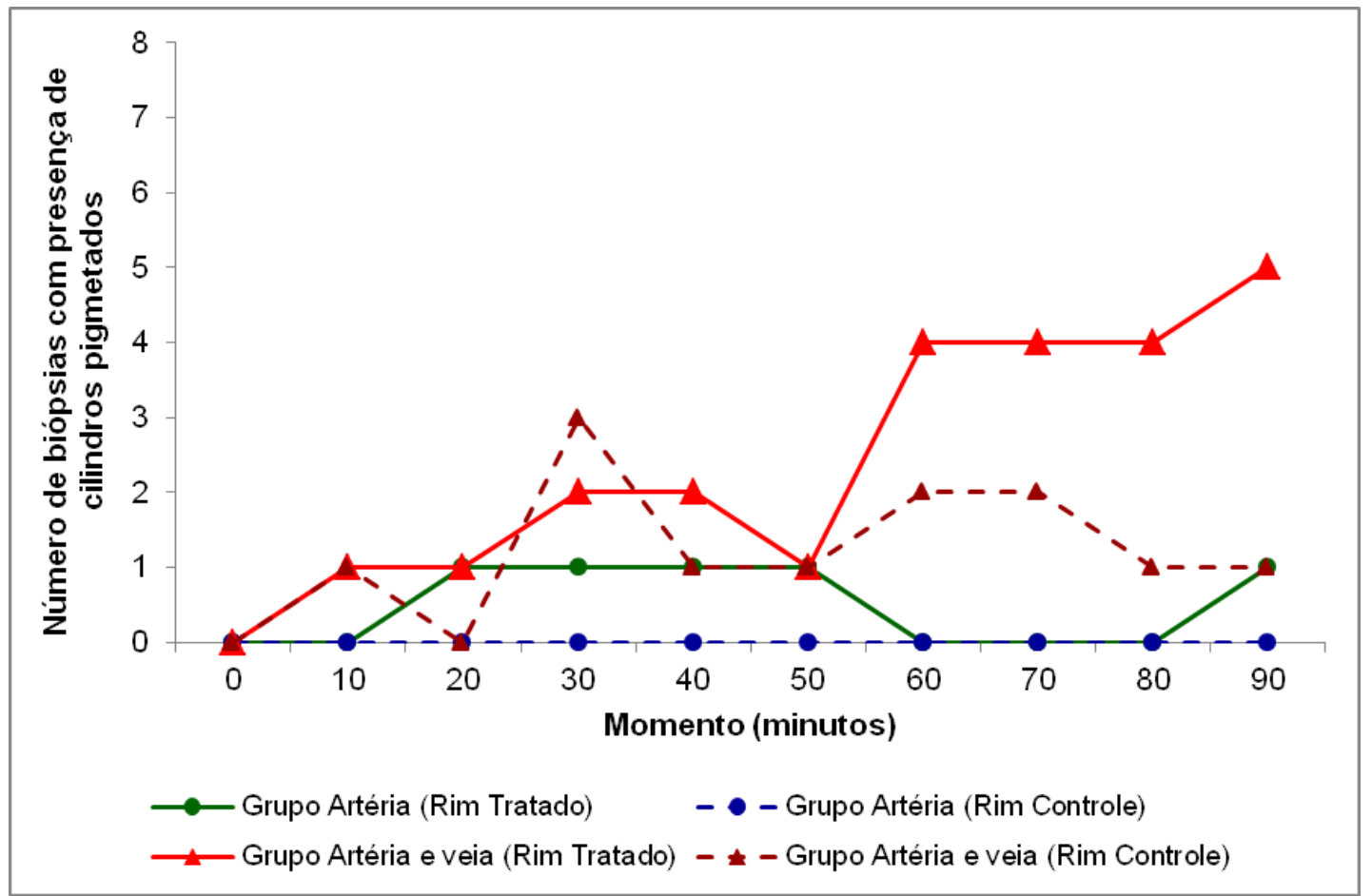

Figura 9. Distribuição do número de biópsias com presença de cilindros pigmentados 
Tabela 5. Distribuição do número de biópsias com hemorragia intersticial

\begin{tabular}{lcccc}
\hline \multirow{2}{*}{$\begin{array}{l}\text { Momento } \\
\text { (min) }\end{array}$} & \multicolumn{3}{c}{$\begin{array}{c}\text { Artéria } \\
(\mathbf{n}=8)\end{array}$} & \multicolumn{3}{c}{ Tipo de clampeamento } \\
\cline { 2 - 5 } & $\begin{array}{c}\text { Rim esquerdo } \\
\text { (Isquêmicia e Veia } \\
\mathbf{n}(\%)\end{array}$ & $\begin{array}{c}\text { Rim direito } \\
\text { (Controle) } \\
\mathbf{n}(\%)\end{array}$ & $\begin{array}{c}\text { Rim esquerdo } \\
\text { (Isquêmico) } \\
\mathbf{n}(\%)\end{array}$ & $\begin{array}{c}\text { Rim direito } \\
\text { (Controle) } \\
\mathbf{n}(\%)\end{array}$ \\
\hline 0 & $0(0,0)$ & $1(12,5)$ & $1(12,5)$ & $0(0,0)$ \\
10 & $3(37,5)$ & $0(0,0)$ & $0(0,0)$ & $0(0,0)$ \\
20 & $2(25,0)$ & $2(25,0)$ & $1(12,5)$ & $1(12,5)$ \\
30 & $2(25,0)$ & $1(12,5)$ & $0(0,0)$ & $0(0,0)$ \\
40 & $1(12,5)$ & $2(25,0)$ & $1(12,5)$ & $2(25,0)$ \\
50 & $1(12,5)$ & $3(37,5)$ & $1(12,5)$ & $1(12,5)$ \\
60 & $3(37,5)$ & $3(37,5)$ & $0(0,0)$ & $3(37,5)$ \\
70 & $3(37,5)$ & $4(50,0)$ & $0(0,0)$ & $2(25,0)$ \\
80 & $5(62,5)$ & $5(62,5)$ & $0(0,0)$ & $2(25,0)$ \\
90 & $5(62,5)$ & $4(50,0)$ & $0(0,0)$ & $1(12,5)$ \\
\hline
\end{tabular}

Dados descritos por número de biópsias e porcentagem sobre o total de biópsias.

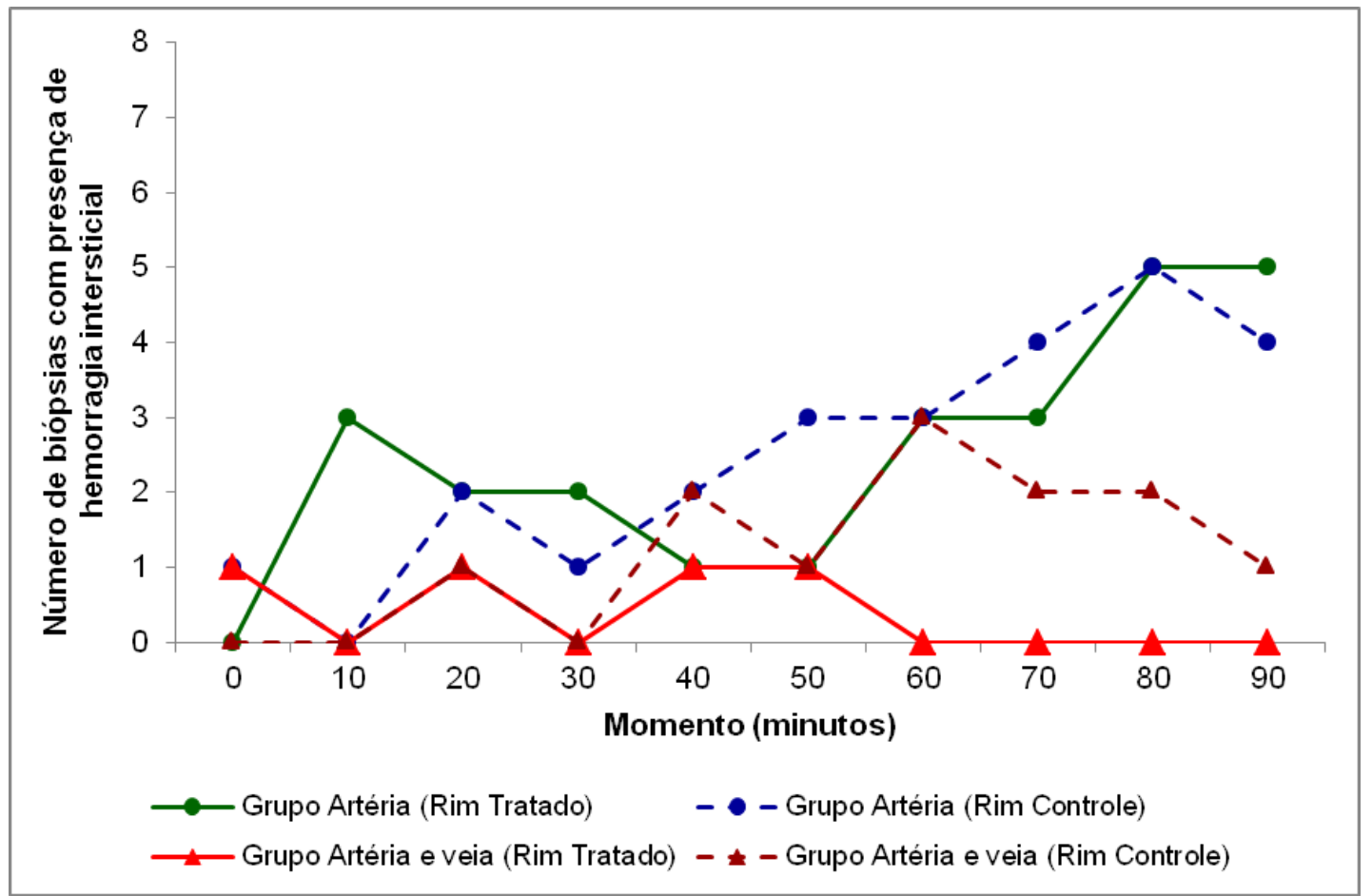

Figura 10. Distribuição do número de biópsias com hemorragia intersticial 


\subsection{Avaliação da presença de lesões nas biópsias}

Com relação aos dados amostrais, para cada biópsia analisada foi verificada a presença de cinco tipos de lesões, portanto em cada grupo de estudo $(n=8)$ seria possível encontrar até 40 lesões. Na figura 11 observamos que o aumento no número destas ocorre proporcionalmente em função do tempo independentemente do grupo de estudo.

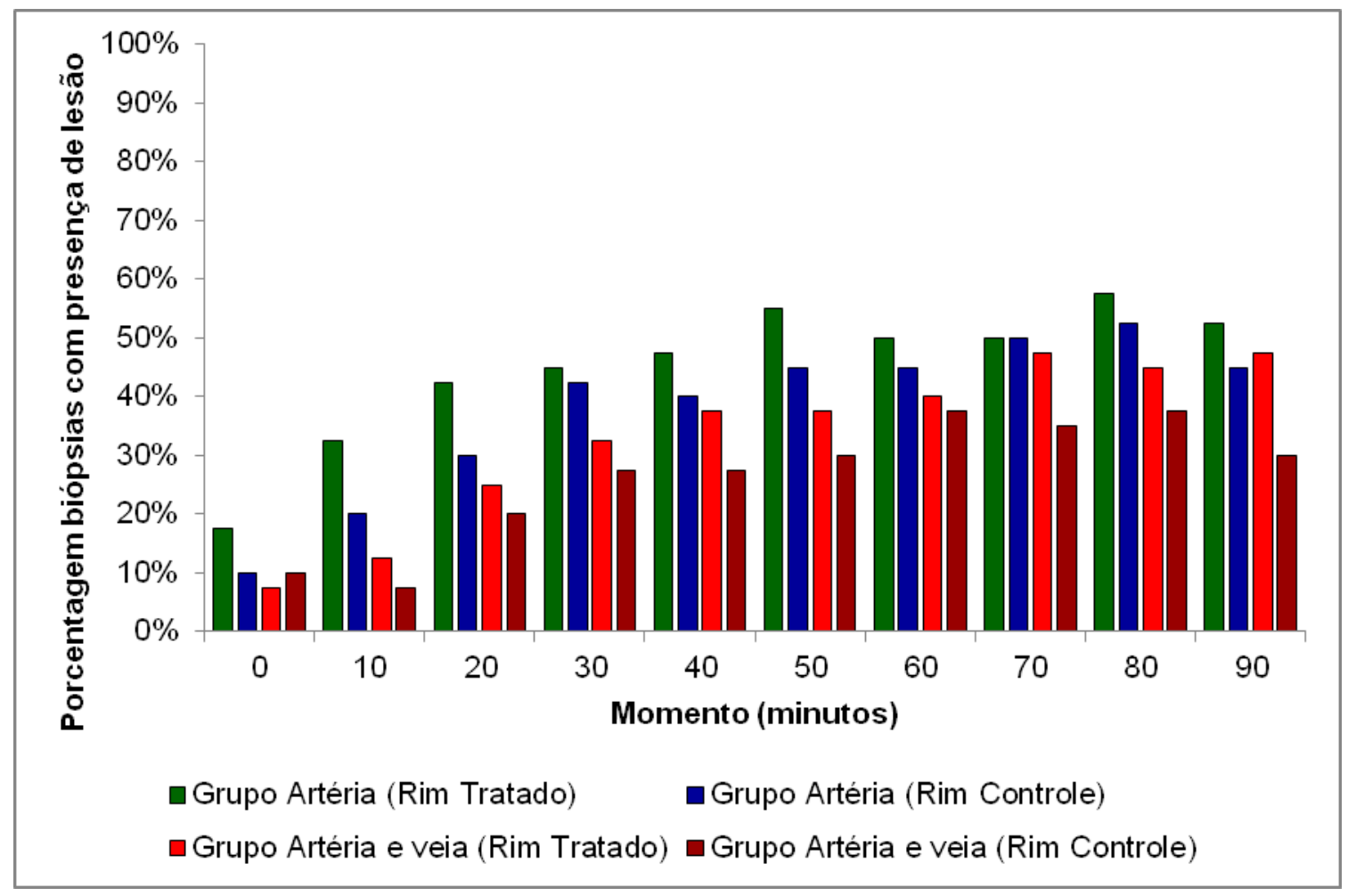

Figura 11. Distribuição da proporção de biópsias com presença de lesão

$\mathrm{Na}$ figura 11 verificamos que tanto para o rim controle (ausência de clampeamento) quanto para o rim isquêmico (clampeado) há um crescimento diretamente proporcional da manifestação de alterações em função do tempo. Esta evidência demonstra que há interação entre o grupo de estudo e o momento de avaliação $(p<0,001)$, ou seja, há evidências de que a variação na proporção de lesões dependa do grupo de estudo.

Devido a essa interação, foram realizadas comparações entre os momentos dentro de cada grupo e comparações entre grupos nos diferentes 
momentos. As proporções de lesão estimadas pelo modelo são apresentadas na tabela 6 e na figura 12.

Tabela 6. Proporções estimadas para a presença de lesão nas biópsias realizadas

\begin{tabular}{|c|c|c|c|c|}
\hline \multirow{3}{*}{$\begin{array}{l}\text { Momento } \\
\text { Basal } \\
\text { (min) }\end{array}$} & \multicolumn{4}{|c|}{ Tipo de clampeamento } \\
\hline & \multicolumn{2}{|c|}{ Artéria e veia } & \multicolumn{2}{|c|}{ Artéria } \\
\hline & $\begin{array}{c}\text { Rim controle } \\
\mathrm{n}(\%)\end{array}$ & $\begin{array}{c}\text { Rim isquêmico } \\
\mathrm{n}(\%)\end{array}$ & $\begin{array}{c}\text { Rim controle } \\
\mathrm{n}(\%)\end{array}$ & $\begin{array}{c}\text { Rim isquêmico } \\
n(\%)\end{array}$ \\
\hline 0 & $10,0(3,5)$ & $7,5(4,9)$ & $10,0(7,1)$ & $17,5(6,6)$ \\
\hline 10 & $7,5(3,4)$ & $12,5(4,9)$ & $20,0(3,5) \$$ & $32,5(4,9) \$$ \\
\hline 20 & $20,0(5,0)$ & $25,0(5,9) \$$ & $30,0(6,1) \$$ & $42,5(6,6) \$$ \\
\hline 30 & $27,5(7,0)$ & $32,5(4,9) \$$ & $42,5(7,4) \$$ & $45,0(5,9) \$$ \\
\hline 40 & $27,5(6,1)$ & $37,5(5,5) \$$ & $40,0(5,0) \$$ & $47,5(7,0) \$$ \\
\hline 50 & $30,0(5,0) \$$ & $37,5(6,6) \$$ & $45,0(6,8) \$$ & $55,0(5,9) \$$ \\
\hline 60 & $37,5(8,2) \$$ & $40,0(7,1) \$$ & $45,0(6,8) \$$ & $50,0(7,1) \$$ \\
\hline 70 & $35,0(8,5) \$$ & $47,5(7,0) \$$ & $50,0(8,7) \$$ & $50,0(5,0) \$$ \\
\hline 80 & $37,5(5,5) \$$ & $45,0(7,7) \$$ & $52,5(7,9) \$$ & $57,5(4,2) \$$ \\
\hline 90 & $30,0(9,4)$ & $47,5(7,0) \$$ & $45,0(8,5) \$$ & $52,5(8,6) \$$ \\
\hline
\end{tabular}

\$: Diferença significante em relação ao basal. Dados representam proporções estimadas e erros padrão obtidos com modelo de equações de estimação generalizadas.

Os valores em destaque na tabela acima indicam os tempos a partir dos quais há um aumento significativo no número de lesões para diferentes tipos de clampeamento. Para o Grupo A os valores são significativos a partir de 10 minutos tanto para rim controle quanto isquêmico, enquanto para o Grupo AV estes valores são de 20 minutos para o rim isquêmico e 50 minutos para o rim controle. 


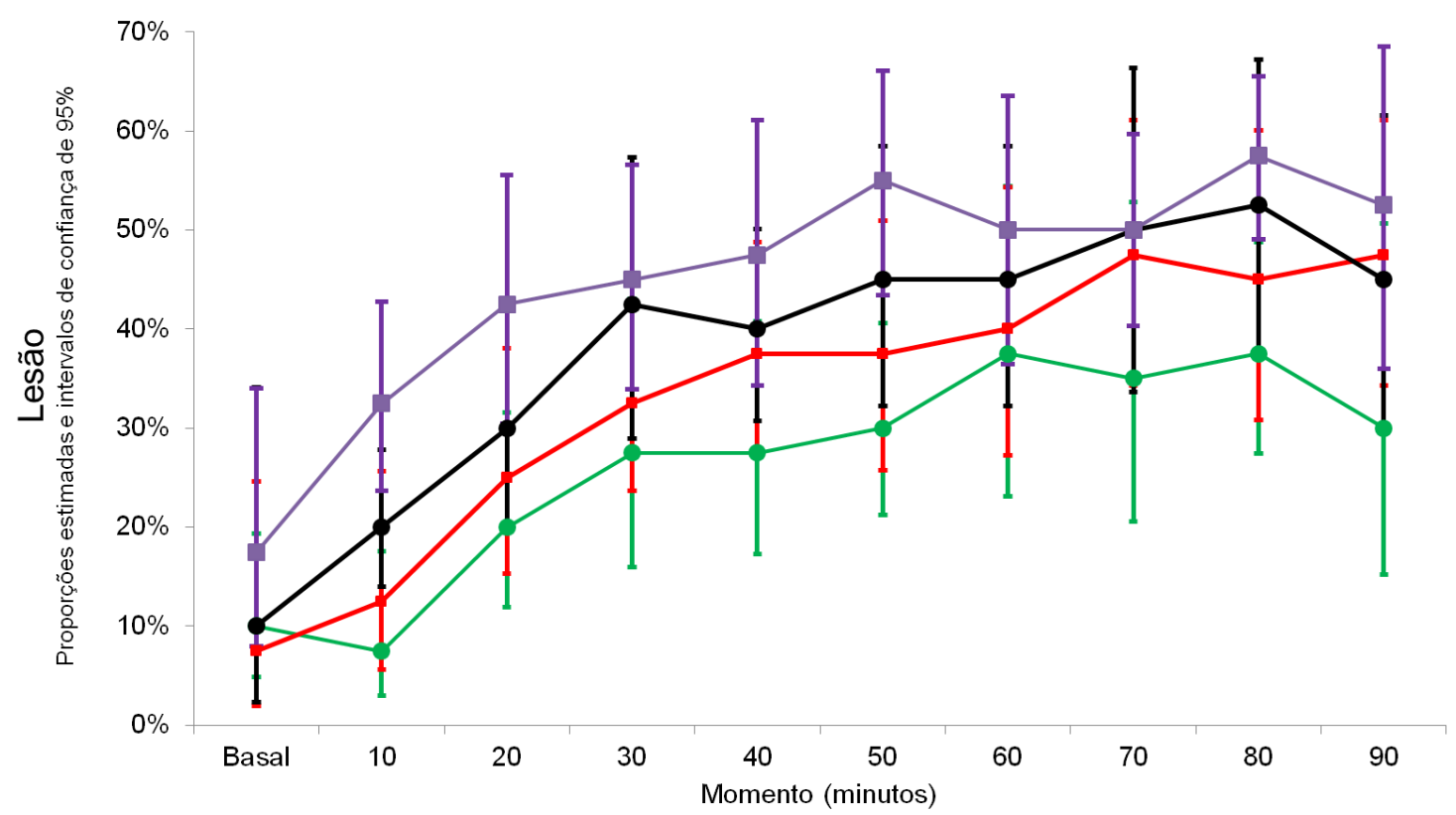

- Artéria e veia (Rim Controle) $\rightarrow$-Artéria e veia (Rim Tratado) $\rightarrow$-Artéria (Rim Controle) - Artéria (Rim Tratado)

Figura 12. Proporções estimadas de lesão e intervalos de confiança de $95 \%$

Ao analisar a figura 12 podemos verificar que para todos os grupos há um perfil de crescimento ligeiramente ascendente para o número de lesões até 30 minutos, independentemente do tipo de grupo de estudo. A partir deste valor identificase uma maior oscilação dependente do tipo de clampeamento.

Estes achados são reforçados durante a análise por comparações múltiplas, nas quais observa-se que para os animais do Grupo AV há evidências de diferenças com relação ao momento inicial entre 50 e 80 minutos para o rim controle e a partir de 20 minutos para o rim isquêmico. Para os animais do Grupo A há evidências de aumento na proporção de lesões a partir de 10 minutos (Tabela 7). 
Tabela 7. Resultados das comparações múltiplas entre momentos quanto à presença de lesões

\begin{tabular}{|c|c|c|c|c|}
\hline \multirow{3}{*}{$\begin{array}{l}\text { Comparação } \\
\text { (min x Basal) }\end{array}$} & \multicolumn{4}{|c|}{ Grupos de estudo } \\
\hline & \multicolumn{2}{|c|}{ Artéria e veia } & \multicolumn{2}{|c|}{ Artéria } \\
\hline & Rim controle & Rim isquêmico & Rim controle & Rim isquêmico \\
\hline 10 & 0,555 & 0,102 & 0,046 & 0,028 \\
\hline 20 & 0,137 & 0,038 & 0,003 & $<0,001$ \\
\hline 30 & 0,135 & 0,004 & 0,001 & $<0,001$ \\
\hline 40 & 0,094 & $<0,001$ & 0,003 & $<0,001$ \\
\hline 50 & 0,008 & $<0,001$ & $<0,001$ & $<0,001$ \\
\hline 60 & 0,001 & 0,001 & 0,003 & $<0,001$ \\
\hline 70 & 0,019 & $<0,001$ & $<0,001$ & $<0,001$ \\
\hline 80 & 0,001 & 0,002 & $<0,001$ & $<0,001$ \\
\hline 90 & 0,137 & $<0,001$ & 0,025 & 0,002 \\
\hline
\end{tabular}

Valores de $\mathrm{p}$ corrigidos pelo método de Bonferroni sequencial.

Ao analisar a tabela 7 podemos verificar que, assim como na tabela 6 , os valores em destaque indicam os tempos a partir dos quais há um aumento significativo no número de lesões, quando comparados ao tempo basal (zero minuto de isquemia). A evidência estatística foi comprovada pelos valores de p expressos na tabela 7, reforçando a ideia que o tempo de segurança a ser adotado para o Grupo A deve ser de 10 minutos de isquemia e de 20 minutos para o rim isquêmico no Grupo AV. 


\section{DISCUSSÃO}

A análise estatística foi descritiva, avaliando as lesões de forma dicotômica (presença ou ausência de lesões), entretanto, ao analisar os gráficos de frequência de distribuição verificamos que há alterações presentes num dado momento amostral, mas esta característica não se repete nos momentos posteriores, este perfil de variabilidade é justificado pelo fato de o local da biópsia não ser exatamente sempre o mesmo.

Analisando a ocorrência de lesões renais apenas em função do tempo verificamos que há interação entre estas duas variáveis $(p<0,001)$, de forma que o número de lesões aumenta proporcionalmente ao tempo de isquemia. Estes resultados são condizentes com os achados na literatura. As amostras oriundas do rim isquêmico evidenciam um maior número de lesões em comparação ao rim controle, que por sua vez apresentou um número menor de lesões.

Ao comparar os resultados dos grupos de estudo A e AV observamos que a maioria das alterações celulares (congestão vascular e edema, alteração degenerativa, infiltrado inflamatório intersticial e hemorragia intersticial) apresentaram maior frequência e prevalência no Grupo A tanto para rim controle quanto para rim isquêmico em comparação ao Grupo AV. No entanto as lesões foram identificadas a partir de 10 minutos para o Grupo $A$, enquanto que as primeiras alterações foram detectadas no Grupo AV a partir de 20 minutos. No Grupo AV a única alteração que se manifestou com maior prevalência e frequência foi a presença de cilindros pigmentados, principalmente a partir de 60 minutos no rim isquêmico. É importante visar que esta alteração não foi observada em nenhum dos momentos analisados no rim controle do Grupo A. Portanto, baseado nestes resultados pode-se evidenciar que há diferença significativa entre os tipos de clampeamento da pelve renal, de forma que uma vez clampeada somente a artéria obtivemos um maior número de alterações renais, indicando que, uma vez clampeado o conjunto veia e artéria renais, teríamos um possível efeito renoprotetor observado neste experimento. Tal resultado contrapõe com estudo feito por Mir et al. no qual sugere que o clampeamento da artéria e veia renal em cirurgia aberta em suínos seria mais prejudicial do que o clampeamento isolado da artéria, onde a presença de refluxo venoso poderia beneficiar a manutenção da homeostasia renal, todavia tal cenário não se repetiu em cirurgias 
laparoscópicas onde a formação de pneumoperitônio prejudica o fluxo venoso. ${ }^{(57)}$ Outro estudo realizado em suínos determinou uma janela isquêmica de 35 minutos na qual o clampeamento da artéria renal produz um grau menor de alterações renais em comparação ao clampeamento da artéria e veia renais. ${ }^{(58)}$

Com relação aos achados relativos ao tempo de corte, os resultados obtidos no Grupo AV (20-30 minutos) são condizentes com os dados obtidos na literatura que estimam o tempo de isquemia entre 25 e 30 minutos, conforme demonstra Volpi em sua revisão de literatura. ${ }^{(5)}$ Entretanto modelos experimentais muitas vezes são desenhados utilizando-se diferentes animais, de modo a dificultar a extrapolação dos achados para ensaios clínicos em humanos devido ao fato de serem animais de espécies diferentes, que possuem fisiologia e anatomia distintas. ${ }^{(6)}$

Com relação a estudos em humanos há linhas que consideram que o rim é capaz de suportar de 30 a 60 minutos de isquemia sem danos à função renal. ${ }^{(59)}$ A maior parte dos estudos clínicos ou estudos retrospectivos consideram desenhos de estudo que contemplam diferentes tipos de abordagem cirúrgica (aberta, laparoscópica e robótica), realizam dosagem de ureia e creatinina antes e depois do procedimento cirúrgico e acompanham o pacientes por horas, dias ou meses com a finalidade de identificar tempo de recuperação renal (janela isquêmica). ${ }^{\left({ }^{34)}\right.}$ Com relação ao tipo de clampeamento, além da oclusão arterial ou artéria e veia, estudos como os de Simonns et al. e Secin et al. verificaram a viabilidade de técnicas como o clampeamento manual (com objetivo de manter o máximo de oxigenação nos tecidos), isquemia zero (ausência de isquemia - neste caso deve-se levar em consideração o tipo, tamanho e nível de infiltração do tumor em nefrectomias parciais) e pinçamento seletivo de ramos da artéria renal com pinças micro-bulldogs para promover uma isquemia global evitando perda de líquidos durante o procedimento. ${ }^{(3,5,7)}$

Por fim, estudo realizado por Chan et al. sugerem que o clampeamento arterial deve ser evitado por resultar em vasoespasmos que estariam diretamente relacionados com disfunção renal. ${ }^{(25,60)}$

É de conhecimento que a lesão renal é até certo ponto reversível, a identificação do tempo de transição para o tipo irreversível também é uma das lacunas a serem preenchidas no estudo da isquemia, variáveis como a técnica cirúrgica, idade do paciente, presença de comorbidades como diabetes e hipertensão, vascularização arterial e função renal pré-operatória requerem que o insulto isquêmico perdure o mínimo possível, sendo sugerida a indução de hipotermia após 30 minutos de 
isquemia. $^{(5)}$

Os trabalhos realizados por Lane et al. consideram como tempo de corte para segurança do procedimento cirúrgico 20 minutos de isquemia quente e sugerem a mudança de estratégia para isquemia fria quando a manobra cirúrgica requerer até 2 horas de procedimento, de forma a reduzir os danos renais gerados pela isquemia. Entretanto, autores notificam que a inserção de gelo para manutenção das funções renais deve perdurar o mínimo possível (máximo 35 minutos). ${ }^{(23)}$

Os efeitos que estão associados ao insulto agudo estão atrelados a 3 mecanismos interligados: alterações vasculares por alterações vasoconstritoras persistentes em decorrência da resposta das células endoteliais ao mecanismo compensatório; obstrução das células tubulares por resíduos de membrana fazendo com que haja o extravasamento do filtrado glomerular para o lúmen reduzindo a TFG e o terceiro mecanismo está atrelado à lesão por reperfusão após restabelecimento do fluxo sanguíneo, promovendo alterações tais como perturbação celular, hipercoagulabilidade e congestão microvascular. Estratégias farmacológicas vêm sendo discutidas, tais como a oclusão manual em contrapartida à oclusão permanente, uso de agentes vasodilatadores como dopamina e ditiazem e uso de fármacos protetores. ${ }^{(61)} \mathrm{O}$ uso de agentes farmacológicos há décadas vem sendo estudado como estratégia protetora para efeitos negativos da isquemia, mas até o momento não há nenhuma droga consolidada. Resultados mais promissores têm sido observados com a metilprednisolona e dexametasona, cujo mecanismo de ação pode suprimir a expressão de radicais livres e proteases lisossomais, reduzindo a produção de citocinas por meio da atenuação de neutrófilos e inibição da expressão de moléculas de adesão ICAM e VCAM. Estudos atuais demonstram que o uso da metilprednisolona previne a formação de infiltrado inflamatório instersticial, podendo ser considerada uma estratégia farmacológica para este tipo de alteração celular. ${ }^{(25)}$

É importante considerar que fatores como a manutenção do plano anestésico, monitorização da pressão arterial e hidratação são fundamentais para estabilidade hemodinâmica e redução dos efeitos negativos do procedimento na função renal. ${ }^{(20)}$

A aplicabilidade destes achados serve como guia para desenho de protocolo de ensaios clínicos, haja vista que para pacientes com função renal préoperatória normal é considerado tempo de segurança de 30 minutos para indução do insulto isquêmico, sendo questionada por pesquisadores que a consideram um 
algorítimo falho ${ }^{(23,30)}$ os quais sugerem que a quantidade e qualidade de parênquima renal remanescentes interferem diretamente no restabelecimento da função renal; no entanto, para confirmação desta hipótese uso de novos biomarcadores, assim como testes imunohistoquímicos mais sensíveis são requeridos. ${ }^{(62)}$

Verificamos na literatura que há evidências de que a ocorrência de lesão renal aguda derivada do evento isquemia-reperfusão pode levar à disfunção de órgãos tais como o pulmão, cérebro, fígado, coração e outros órgãos, caracterizando assim o fenômeno denominado crosstalk. Baseado neste conceito poderíamos justificar a identificação de lesões renais nos rins contralaterais dos animais estudados. Em termos fisiopatológicos, a lesão por isquemia-reperfusão promove a ativação de mediadores pró-inflamatórios e pró-apoptóticos, além da geração de estresse oxidativo e espécies reativas de oxigênio produção (ROS), que levam à modificação dos níveis de citocinas vasoativas (TNF- $\alpha, \mathrm{IL}-1 \beta, \mathrm{IL}-6, \mathrm{IL}-12$, IL-15, IL-18, IL-32, e endotelina-1) e quimiocinas como produto da adesão de leucócitos-endoteliais e à ativação de leucócitos (processo característico da lesão isquêmica). ${ }^{(63)}$

O presente estudo apresentou algumas limitações como o número limitado de animais, a análise estatística foi qualitativa, não abrangendo níveis de lesão renal (leve, moderada e grave).

A lacuna do tempo de isquemia segura depende de inúmeras variáveis intrínsecas e extrínsecas ao procedimento cirúrgico, no entanto a literatura fornece um compilado de estudos que abordam a lesão isquêmica sob diferentes óticas; até o presente momento não há um algoritmo disponível para prever o risco de LRA em pacientes submetidos à isquemia intraoperatória, considera-se que a avaliação pré-operatória e o planejamento da melhor estratégia para cada caso trarão melhores resultados pós-operatórios em termos de manutenção da função renal. 


\section{CONCLUSÕES}

1. O número de lesões derivadas da isquemia tem associação com o tempo de duração do insulto.

2. Além disso, verificou-se que há diferença significativa entre os tipos de clampeamento, sendo que o Grupo AV apresentou menor frequência de lesões do que o Grupo A (apresentou maior número de lesões em menor intervalo de tempo de isquemia).

3. O tempo de segurança encontrado para o Grupo A foi de 10 minutos e para o Grupo AV de 20 minutos; a frequência de alterações morfológicas e estruturais renais apresentou relação com o tipo de clampeamento e a sua duração. 
7 REFERÊNCIAS

1. Abuelo JG. Normotensive ischemic acute renal failure. N Engl J Med. 2007;357(8):797-805.

2. Cunha MS, Bandeira NG. [Ischemia and reperfusion of tissues]. Rev Soc Bras Cir Plast. 2007;22(3):170-5. Portuguese.

3. Simmons MN, Schreiber MJ, Gill IS. Surgical renal ischemia: a contemporary overview. J Urol. 2008;180(1):19-30.

4. Himmelfarb J, Joannidis M, Molitoris B, Schietz M, Okusa MD, Warnock D, et al. Evaluation and initial management of acute kidney injury. Clin J Am Soc Nephrol. 2008;3(4):962-7.

5. Volpe A, Blute ML, Ficarra V, Gill IS, Kutikov A, Porpiglia F, et al. Renal ischemia and function after partial nephrectomy: a collaborative review of the literature. Eur Urol.

2015;68(1):61-74.

6. Badr KF, Ichikawa I. Prerenal failure: a deleterious shift from renal compensation to decompensation. N Engl J Med. 1988;319(10):623-9.

7. Secin FP. Importance and limits of ischemia in renal partial surgery: experimental and clinical research. Adv Urol. 2008:102461.

8. Goes N, Urmson J, Ramassar V, Halloran PF. Ischemic acute tubular necrosis induces an extensive local cytokine response. Evidence for induction of interferon-gamma, transforming growth factor-beta 1, granulocyte-macrophage colony-stimulating factor, interleukin-2, and interleukin-10. Transplantation. 1995;59(4):565-72.

9. Liu M, Liang Y, Chigurupati S, Lathia JD, Pletnikov M, Sun Z, et al. Acute kidney injury leads to inflammation and functional changes in the brain. J Am Soc Nephrol. 2008;19(7):1360-70.

10. Crane NJ, Huffman SW, Alemozaffar M, Gage FA, Levin IW, Elster EA. Evidence of a heterogeneous tissue oxygenation: renal ischemia/reperfusion injury in a large animal model. J Biomed Opt. 2013;18(3):035001.

11. Li C, Jackson RM. Reactive species mechanisms of cellular hypoxia-reoxygenation injury. Am J Physiol Cell Physiol. 2002;282(2):C227-41.

12. Costa JA, Vieira-Neto OM, Moysés Neto M. [Acute renal failure]. Medicina (Ribeirão Preto). 2003;36:307-24. [Presented at Simpósio Urgências e Emergências em Clínica Médica, 2003; [place unknown]. Portuguese.

13. Thompson RH, Franck I, Lohse CM, Saad IR, Fergany A, Zincke H, et al. The impact of time during open nephron sparing surgery on solitary kidneys: a multi-institutional study. $J$ Urol. 2007;177(2):471-6.

14. Porter J. Renal ischemia during partial nephrectomy: does every minute still count? Eur Urol. 2015;68(1):75-7.

15. Becker F, Van Poppel H, Hakenberg OW, Stief C, Gill I, Guazzoni G, et al. Assessing the impact of ischaemia time during partial nefrechtomy. Eur Urol. 2009;56(4):625-35. 
16. Baument, $\mathrm{H}$. Ballaro A, Shach $\mathrm{N}$. et al. Reducing warm ischaemia time during laparoscopic partial nephrectomy: a prospective comparison of two renal closure tecnhiques. Eur Urol. 2007;52(4):1164-9.

17. Devarajan P. Update on mechanisms of ischemic acute kidney injury. J Am Soc Nephrol. 2006;17(6):1503-20.

18. Orvieto MA, Zorn KC, Mendiola F, Lyon MB, Mikhail AA, Gofrit ON, et al. Recovery of renal function after complete renal hilar versus artery alone clamping during open and laparoscopic surgery. J Urol. 2007;177(6):2371-4.

19. McDougal WS. Renal perfusion/reperfusion injuries. J Urol. 1988;140(6):1325-30.

20. Jablonski P, Howden BO, Rae DA, Birrell CS, Marshall VC, Tange J. An experimental model for assessment of renal recovery from warm ischemia. Transplantation. 1983;35(3):198204.

21. Myers BD, Miller DC, Mehigan JT, Olcott CO 4th, Golbetz H, Robertson CR, et al. Nature of the renal injury following total renal ischemia in man. J Clin Invest. 1984;73(2):329-41.

22. Kelly KJ. Distant effects of experimental renal ischemia/reperfusion injury. J Am Soc Nephrol. 2003;14(6):1549-58.

23. Lane BR, Babineau DC, Poggio ED, Weight CJ, Larson BT, Gill IS, et al. Factors predicting renal functional outcome after partial nephrectomy. J Urol. 2008;180(6):2363-8; discussion 2368-9.

24. Wang F, Yu G, Liu SY, Li JB, Wang JF, Bo LL, et al. Hydrogen-rich saline protects against renal ischemia/reperfusion injury in rats. J Surg Res. 2011;167(2):e339-44.

25. Klatte T, Ficarra V, Gratzke C, Kaouk J, Kutikov A, Macchi V, et al. A literature review of renal surgical anatomy and strategies for partial nephrectomy. Eur Urol. 2015;68(6):980-92.

26. Ward JP. Determination of the optimum temperature for regional renal hypothermia during temporary renal ischaemia. Br J Urol. 1975;47(1):17-24.

27. Henriksen JH, Petersen HK. Renal blood flow and metabolism after cold ischaemia: peroperative measurements in patients with calculi. Clin Physiol. 1984;4(1):41-50.

28. Parekh DJ, Weinberg JM, Ercole B, Torkko KC, Hilton W, Bennett M, et al. Tolerance of the human kidney to isolated controlled ischemia. J Am Soc Nephrol. 2013;24(3):506-17.

29. Orvieto MA, Zorn KC, Mendiola FP, Gong EM, Lucioni A, Mikhail AA, et al. Ischemia preconditioning does not confer resilience to warm ischemia in a solitary porcine kidney model. Urology. 2007;69(5):984-7.

30. Rocca RS. Impact of acute ischemia on human kidney. In: Marberger M, Dreikon K, editors. Renal preservation. Baltimore: Williams \& Wilkins 1983, p. 21-2.

31. Choi JD, Park JW, Lee SY, Jeong BC, Jeon SS, Lee HM, et al. Does prolonged warm ischemia after partial nephrectomy under pneumoperitoneum cause irreversible damage to the affected kidney? J Urol. 2012;187(3):802-6. 
32. Yossepowitch O, Eggener SE, Serio A, Huang WC, Snyder ME, Vickers AJ, et al. Temporary renal ischemia during nephron sparing surgery is associated with short-term but not long-term impairment in renal function. J Urol. 2006;176(4 Pt 1):1339-43; discussion 1343.

33. Pahernik S, Roos F, Röhrig B, Wiesner C, Thüroff JW. Elective nephron sparing surgery for renal cell carcinoma larger than $4 \mathrm{~cm}$. J Urol. 2008;179(1):71-4; discussion 74.

34. Thompson RH, Lane BR, Lohse CM, Leibovich BC, Fergany A, Frank I, et al . Every minute counts when the renal hilium is clamped during partial nephrectomy. Eur Urol. 2010;58(3):3405.

35. Doty JM, Saggi BH, Blocher CR, Fakhry I, Gehr T, Sica D, et al. Effects of increased renal parenchymal pressure on renal function. J Trauma. 2000;48(5):874-7.

36. Kim TS, Oh JH, Rhew HY. "Off-clamp, non-renorrhaphy" laparoscopic partial nephrectomy with perirenal fat and Gerota's fascia reapproximation: initial experience and perioperative outcomes. J Laparoendosc Adv Surg Tech A. 2014;24(5):339-44.

37. Desai MM, Gill IS, Ramani AP, Spaliviero M, Rybicki L, Kaouk JH. Then impact of warm ischaemia on renal function after laparoscopic partial nephrectomy. BJU Int 2005;95(3):377-83.

38. McDougal WS. Renal perfusion/reperfusion injuries. J Urol. 1988;140(6):1325-30.

39. Brodsky SV, Yamamoto T, Tada T, Kim B, Chen J, Kajiya F, et al. Endothelial dysfunction in ischemic acute renal failure: rescue by transplanted endothelial cells. Am J Physiol Renal Physiol. 2002; 282(6):F1140-9.

40. El Sabbahy M, Vaidya VS. Ischemic kidney injury and mechanisms of tissue repair. Wiley Interdiscip Rev Syst Biol Med. 2011;3(5):606-18.

41. Devarajan P. Update on mechanisms of ischemic acute kidney injury. J Am Soc Nephrology. 2006;17(6):1503-20.

42. Quintaes PS, Noronha IL. Revisão/atualização em insuficiência renal aguda: papel dos neutrófilos e moléculas de adesão na fisiopatologia da insuficiência renal aguda isquêmica. $J$ Bras Nefrol. 1998;20(1):74-7.

43. Évora PR, Pearson PJ, Seccombe JF, Schaff HV. [Ischemia-reperfusion lesion. Physiopathologic aspects and the importance of the endothelial function]. Arq Bras Cardiol. 1996;66(4):239-45. Portuguese.

44. Gueler F, Gwinner W, Schwarz A, Haller H. Long-term effects of acute ischemia and reperfusion injury. Kidney Int. 2004;66(2):523-7.

45. Bonventre JV. Mediators of ischemic renal injury. Annu Rev Med. 1988;39:531-44.

46. Bonventre JV, Weinberg JM. Recent advances in the pathophysiology of ischemic acute renal failure. J Am Soc Nephrol. 2003;14(8):2199-210.

47. Brady HR, Singer GG. Acute renal failure. Lancet. 1995;346(8989):1533-40.

48. Murray PT, Mehta RL, Shaw A, Ronco C, Endre Z, Kellum JA, et al. Current use of biomarkers in acute kidney injury: report and summary of recommendations from 10th Acute Dialysis Quality Initiative consensus conference. Kidney Int. 2013;85(3):513-21. Epub 2013 Oct 9. 
49. Charlton JR, Portilla D, Okusa MD. A basic science view of acute kidney injury biomarkers. Nephrol Dial Transplant. 2014;29(7):1301-11.

50. Sincos IR, Aun R, da Silva ES, Belczak S, de Lourdes Higuchi M, Gornati VC, et al. Impact of stent-graft oversizing on the thoracic aorta: experimental study in a porcine model. $J$ Endovasc Ther. 2011;18(4):576-84.

51. Sincos IR, da Silva ES, Belczak SQ, Baptista Sincos AP, de Lourdes Higuchi M, Gornati V, et al. Histologic analysis of stent graft oversizing in the thoracic aorta. J Vasc Surg.

2013;58(6):1644-51.e4.

52. Faraway JJ. Extending the linear model with R: generalized linear, mixed effects and nonparametric regression models. Boca Raton: Chapman \& Hall/CRC; 2005.

53. Altman DG. Practical statistics for medical research. London: Chapman \& Hall/CRC; 1991.

54. Vicini L. Análise multivariada da teoria à prática [internet]. Santa Maria: UFSM; 2005 [citado 2017 ago 04]. 215 p. Disponível em:

http://w3.ufsm.br/adriano/livro/Caderno\%20dedatico\%20multivariada\%20-

\%20LIVRO\%20FINAL\%201.pdf

55. Hosmer DW, Lemeshow S. Applied logistic regression. New Jersey: John Wiley \& Sons; 2004.

56. Bussab WO, Morettin PA. Estatística básica. 6a ed. São Paulo: Saraiva; 2010.

57. Mir MC, Ercole C, Takagi T, Zhang Z, Velet L, Remer EM, et al. Decline in renal function after partial nephrectomy: etiology and prevention. J Urol. 2015;193(6):1889-98.

58. Thompson RH, Lane BR, Lohse CM, Leibovich BC, Fergany A, Frank I, et al. Renal function after partial nephrectomy: effect of warm ischemia relative to quantity and quality of preserved kidney. Urology. 2012;79(2):356-60.

59. Bezerra DO, Feitosa ML, Almeida HM, Costa FA, Braga JF, Souza FA, et al. Collared pecary (Tayassu tajacu) as a new model of renal ischemic injury induced by clamping the renal artery. Acta Cir Bras. 2014;29(9):560-72.

60. Chan AA, Wood CG, Caicedo J, Munsell MF, Matin SF. Predictors of unilateral renal function after open and laparoscopic partial nephrectomy. Urology 2010;75(2):295-302.

61. Fernandes-Charpiot IM. Efeito da metilprednisolona na lesão de isquemia e reperfusão renal [tese]. [São José Rio Preto]: Faculdade de Medicina de São José Rio Preto; 2011. 75 f.

62. Simone G, Gill IS, Mottrie A, Kutikov A, Patard JJ, Alcaraz A, et al . Indications techniques, outcomes and limitation for minimally ischemic and off-clamp partial nephrectomy: a systematic review of the literature. Eur Urol. 2015;68(4):632-40.

63. Li X, Hassoun HT, Santora R, Rabb H. Organ crosstalk: the role of the kidney. Curr Opin Crit Care. 2009;15(6):481-7. 


\begin{abstract}
Purpose: This study aims to study renal morphological and structural changes in relation to different ischemic times and types of renal vascular pedicle clamping. Methods: For this, experiments were performed simulating this procedure in which 12 pigs were divided into groups containing 6 animals each: Group AV; unilateral clamping of the renal artery and vein with contralateral kidney used as control and Group A unilateral clamping of the renal artery only, with the contralateral kidney also used as control. Serial biopsies of the renal parenchyma were performed at times $0,10,20,30$, $40,50,60,70,80$, and 90 minutes after vessel clamping. The tissues were submitted to histopathological analysis in order to identify structural and morphological alterations. Results: There is correlation between the occurrence of renal lesions as a function of time ( $p<0.001$ ), mainly after 20 minutes of ischemia; (vascular congestion and edema, interstitial inflammatory infiltrate, interstitial hemorrhage and cell degeneration) were observed, except for the formation of pigmented cylinders that were only found in the AV Group. Conclusion: As a result of this study, we observed that the number of lesions derived from ischemia is associated with the duration of the insult. In addition, it was found that there was a significant difference between the types of clamping, and the AV Group presented a lower frequency of injuries than Group A (it presented a higher number of injuries in a shorter time interval of ischemia). Regarding the safety time found for Group A was 10 minutes and for Group AV of 20 minutes; The frequency of morphological and renal structural changes was related to the type of clamping and its duration.
\end{abstract}




\section{Bibliografia consultada}

Bagshaw SM, Laupland KB, Doig CJ, Mortis G, Fick GH, Mucenski M, et al. Prognosis for longterm survival and renal recovery in critically ill patients with severe acute renal failure: a population-based study. Crit Care. 2005;9(6):R700-9.

Burke TJ, Cronin RE, Duchin KL, Peterson LN, Schrier RW. Ischemia and tubule obstruction during acute failure in dogs: mannitol in protection. Am J Physiol. 1980;238(4):F305-14.

Gill IS, Patil MB, Abreu AL, Ng C, Cai J, Berger A, et al. Zero ischemia anatomical partial nephrectomy: a novel approach. J Urol. 2012;187(3):807-14.

Jablonski P, Howden B, Rae D, Rigol G, Birrell C, Marshall V, et al. The influence of the contralateral kidney upon recovery from unilateral warm renal ischemia. Pathology. 1985;17(4):623-7.

Jacobs SC, Cho E, Dunkin BJ, Flowers JL, Schweitzer E, Cangro C, et al. Laparoscopic live donor nephrectomy: the University of Maryland 3-year experience. J Urol. 2000;164(5):1494-9.

Matin SF, Gill IS, Worley S, Novick AC. Outcome of laparoscopic radical and open partial nephrectomy for the sporadic $4 \mathrm{~cm}$ or less renal tumor with a normal contralateral kidney. $J$ Urol. 2002;168(4 Pt 1):1356-9; discussion 1359-60.

McLoughlin GA, Heal MR, Tyrell IM. An evaluation of techniques used for the production of temporary renal ischaemia. $\mathrm{Br} J$ Urol. 1978;50(6):371-5.

Porpiglia F, Fiori C, Bertolo R, Morra I, Russo R, Piccoli G, et al. Long-term functional evaluation of the treated kidney in a prospective series of patients who underwent laparoscopic partial nephrectomy for small renal tumors. Eur Urol. 2012;62(1):130-5.

Rais-Bahrami S, George AK, Herati AS, Srinivasan AK, Richstone L, Kavoussi LR. Off-clamp versus complete hilar control laparoscopic partial nephrectomy: comparison by clinical stage. BJU Int. 2012;109(9):1376-81.

Riggs SB, Larochelle JC, Belldegrun AS. Partial nephrectomy: a contemporary review regarding outcomes and different techniques. Cancer J. 2008;14(5):302-7.

Shao P, Tang L, Li P, Xu Y, Qin C, Cao Q, et al. Precise segmental renal artery clamping under the guidance of dual-source computed tomography angiography during laparoscopic partial nephrectomy. Eur Urol 2012;62:1001-8.

Zhou J, Liu Y, Tang Y, Liu F, Zhang L, Zeng X, et al. A comparison of RIFLE, AKIN, KDIGO, and Cys-C criteria for the definition of acute kidney injury in critically ill patients. Int Urol Nephrol. 2016;48(1):125-32. 